\title{
Development of Larval Muscle Properties in the Embryonic Myotubes of Drosophila melanogaster
}

\author{
Kendal S. Broadie and Michael Bate \\ Department of Zoology, University of Cambridge, Cambridge CB2 3EJ, United Kingdom
}

The entire developmental history of muscle membrane electrogenesis can be observed in the embryonic myotubes of Drosophila. We have examined the development of ionic currents and muscle properties using whole-cell patch-clamp techniques throughout embryonic myogenesis. In the early stages of myogenesis, from myoblast fusion through to establishing epidermal insertions, the myotubes are electrically inert and are electrically and dye coupled to adjacent myotubes. Membrane electrogenesis begins in the mid-embryonic stages (early stage 16), when the myotubes abruptly uncouple, revealing the first of five prominent extrajunctional currents: a small, inward, voltage-gated calcium current $\left(I_{\mathrm{ca}}\right)$. The uncoupling of the embryonic myotubes heralds the onset of extremely rapid electrogenesis; within several minutes both the fast, inactivating $\left(I_{A}\right.$; Shaker) and delayed, noninactivating $\left(I_{K}\right)$ outward potassium currents, the stretch-activated outward potassium current, and the junctional glutamate-gated inward current all appear and begin to develop in a current-specific manner. Very late in embryogenesis (late stage 17), the calcium-dependent, outward potassium currents [rapid, inactivating ( $I_{\mathrm{CF}}$; slowpoke) then delayed, noninactivating $\left.\left(I_{\mathrm{cs}}\right)\right]$ develop, completing the complement of macroscopic currents in the mature larval muscle. Hence, the voltage-gated currents $\left(I_{\mathrm{Ca}}, I_{\mathrm{A}}\right.$, and $I_{\mathrm{K}}$, respectively) appear relatively early, and the calcium-dependent currents $\left(I_{C F}, I_{C s}\right)$ appear only very late during myogenesis. This developmental progression of current maturation is reflected in dynamic changes in the voltage responses of the embryonic membrane, from wholly passive response to current injection in the early, coupled myotubes to regenerating, overshooting action potentials in the mature embryonic muscle.

The earliest embryonic $I_{A}$ current has a midpoint of inactivation $\mathbf{4 0} \mathrm{mV}$ more negative than the $I_{A}$ current in the mature embryo. As myogenesis proceeds, the inactivation curve develops a biphasic character, suggesting that a low-inactivation $I_{A}$ channel is present in early development and progressively replaced by the mature form as development proceeds. The current at all stages can be completely eliminated

\footnotetext{
Received Mar. 2, 1992; revised July 13, 1992; accepted July 14, 1992.

We are grateful to Dr. Roger Hardie for excellent advice, technical and otherwise, throughout the course of this study. We thank Drs. Barry Ganetzky and ChunFang Wu for fly stocks, and Drs. Roger Hardie, Helen Skaer, and Rachel Drysdale for critically reading earlier versions of the manuscript. This work was supported by an Oliver Gatty studentship and AFCU scholarship to K.S.B. and by grants from the Hasselblad Foundation and Wellcome Trust to M.B.

Correspondence should be addressed to Kendal Broadie, Department of Zoology, Downing Street, Cambridge CB2 3EJ, UK.

Copyright (C) 1993 Society for Neuroscience $0270-6474 / 93 / 130167-14 \$ 05.00 / 0$
}

in Shaker mutants ( $S h^{\mathrm{ks} 133}$ ). These findings suggest that an embryonic form of the Shaker $I_{A}$ channel is present during early myogenesis. The prominent $I_{A}$ current present in early development is almost entirely inactivated at the physiological resting potential; the significance and mechanism of this developmental shift are unclear.

IKey words: Drosophila, myogenesis, muscle development, excitable membranes, potassium currents, Shaker, slowpoke, calcium currents, invertebrate embryogenesis]

Within $12 \mathrm{hr}$, the musculature of the Drosophila embryo develops from unfused myoblasts to contractile, syncytial muscle fibers with all the characteristics of the mature larval muscles. During this period of rapid differentiation, the myoblasts fuse to form an intricate pattern of syncytial myotubes, the myotubes extend filopodial processes on the epidermis and establish specialized epidermal insertion sites, and the myotubes differentiate a wide array of specialized muscle properties to become functional, contractile larval muscles. In previous work (Bate, 1990), we have examined the earlier stages of this myogenic pathway: the patterning of the fusing myoblasts and the establishment of muscle-specific epidermal insertion sites. In the present study, we focus attention on the later stages of myogenesis: the development of muscle-specific properties in the fully patterned myotubes during late embryogenesis, with particular emphasis on the electrogenesis of the ionic currents responsible for the generation and regulation of the muscle contractile properties.

The ionic currents underlying Drosophila larval muscle properties have been the subject of intense study (Salkoff and Wyman, 1981; Wu and Haugland, 1985; Ganetzky and Wu, 1986; Singh and $\mathrm{Wu}, 1990)$. Five voltage-gated currents control muscle excitation in the mature larval muscles. These currents include an inward calcium current $\left(I_{\mathrm{Ca}}\right)$ and four outward potassium currents; two voltage-gated $\mathrm{K}^{+}$currents, the fast $I_{\mathrm{A}}$ and delayed $I_{\mathrm{K}}$, and two calcium-gated $\mathrm{K}^{+}$currents, the fast $I_{\mathrm{CF}}$ and delayed $I_{\mathrm{CS}}$. In addition, there is a glutamate-gated current at the ncuromuscular junction (NMJ) (Jan and Jan, 1976a,b; Broadie and Bate, 1992). These elements combine in an excitation-contraction cascade that follows familiar lines: a nerve impulse triggers glutamate release at the NMJ, eliciting a nonspecific cation current at the postsynaptic membrane; the muscle is depolarized, thus opening voltage-gated calcium channels, mediating muscle contraction. Outward potassium currents, both voltage and calcium gated, open, counteracting the depolarizing calcium current and returning the muscle to its resting state.

Several of the ionic channels underlying these currents have been characterized at a physiological and genetic level. In particular, the $I_{\mathrm{A}}$ channel is known to be encoded by the Shaker 
Table 1. Whole-cell currents in different genotypes at 16 hr AEL

\begin{tabular}{llll} 
& $I_{\mathrm{A}}$ & $I_{\mathbf{K}}$ & $I_{\text {Ca }}$ \\
\hline Wild-type & $441 \pm 38$ & $164 \pm 11$ & $78 \pm 14$ \\
Sh & $(0)$ & $168 \pm 13$ & $85 \pm 12$ \\
slo & $462 \pm 47$ & $176 \pm 16$ & $90 \pm 17$ \\
Sh; slo & $(0)$ & $172 \pm 24$ & $74 \pm 21$
\end{tabular}

This table provides a comparison of whole-cell embryonic muscle currents $\left(I_{\mathrm{A}}\right.$ $I_{\mathrm{K}}$, and $\left.I_{\mathrm{C} \mathrm{a}}\right)$ at $16 \mathrm{hr} \mathrm{AEL}$ in the different genotypes used in this study. The $S h^{\mathrm{KS} 133}$ mutant specifically eliminates $I_{\mathrm{A}}$ but does not significantly alter $I_{\mathrm{K}}$ or $I_{\mathrm{Ca}}$. Likewise, the slo mutant specifically eliminates $I_{(\mathrm{F}}$ (develops later; see Fig. 7) but does not significantly alter $I_{\mathrm{A}}, I_{\mathrm{k}}$, or $I_{\mathrm{Ca}}$. Each value is the mean $\pm \mathrm{SD}$ of at least five independent observations.

locus (Jan et al., 1977; Salkoff and Wyman, 1981) and the $I_{\mathrm{CF}}$ channel encoded by the slowpoke (slo) locus (Elkins et al., 1986; Elkins and Ganetzky, 1988). Mutations in both genes allow the specific removal of their gene products and subsequent physiological analysis of the remaining muscle currents. Conclusions based on these mutant analyses can be extended and confirmed with conventional ion-substitution and pharmacological blocking experiments (Singh and $\mathrm{Wu}, 1990$ ). Studies using cultured embryonic myotubes (Zagotta et al., 1988) have shown that these cells are amenable to whole-cell patch-clamp analysis. We have developed techniques to dissect intact embryos throughout cmbryogenesis and expose the developing somatic muscles to a detailed analysis in whole-cell patch-clamp configuration using a combination of all these tools. This detailed characterization is unique to Drosophila and provides invaluable tools for the dissection of the complex whole-cell current.

In the present study, we employ these methods to dissect the physiological development of the maturing myotubes during Drosophila embryogenesis. The early embryonic myotubes have no detectable voltage-gated channels, but by the end of embryogenesis, the mature embryonic muscle has all five prominent extrajunctional current-carrying systems and a large synaptic current at the NMJ. We find that these currents appear and develop according to a strict developmental program. The earliest myotubes are electrically coupled and appear electrically inert, with no channel activity detectable in cell-attached patches. A small, inward calcium current is the first macroscopic current revealed after the myotubes uncouple. Uncoupling heralds the rapid onset of electrogenesis, but it is unclear if this sequence represents cause and effect, or is simply incidental. The voltage-gated potassium currents $\left(I_{\mathrm{A}}, I_{\mathrm{K}}\right)$, a stretch-activated potassium current, and the synaptic glutamate-gated current all appear within minutes of myotube uncoupling. The calcium-gated potassium currents $\left(I_{\mathrm{CF}}, I_{\mathrm{CS}}\right)$ do not appear during this initial stage of electrogenesis, arising only very late in embryogenesis and contributing negligibly to the whole-cell current.

Most of the embryonic currents appear indistinguishable from the mature currents in the larval muscles. A notable exception is the early embryonic $I_{\mathrm{A}}$ current, which has a midpoint of inactivation $40 \mathrm{mV}$ more negative than the mature current. It appears that the $I_{\mathrm{A}}$ current is progressively replaced by a current with the mature inactivation profile during development. However, the $I_{\mathrm{A}}$ current at all stages can be eliminated with a null mutant allele of the Shaker locus $\left(S h^{\mathrm{K} \$ 133}\right)$, indicating that both embryonic and mature $I_{A}$ channels are, at least in part, encoded by the Shaker gene. Since the initial $I_{\mathrm{A}}$ current has such a negative inactivation curve, it is apparently inactive at the physi- ological resting potential. Thus, though the $I_{\mathrm{A}}$ current amplitude matures rapidly in early myogenesis, functionally the myotube may experience a much later and gradual onset of the mature $I_{\mathrm{A}}$ form. The mechanism and significance of these dynamic modifications are unclear.

The different components of the whole-cell current appear at very different times, develop with very different time courses, and differ in function according to a dynamic alteration in an inactivation profile. The development of these currents is reflected in the rapidly changing voltage response of the embryonic myotube membrane, which changes from a wholly passive response in early myogenesis, to a strongly suppressed response during mid-embryogenesis, and eventually to a regenerating, overshooting active response in the mature embryo. The functional significance of these changes, if any, remains to be investigated.

\section{Materials and Methods}

\section{Current nomenclature}

A variety of names have been used previously for the $\mathrm{Ca}^{2+}$-gated $\mathrm{K}^{+}$ currents in Drosophila. The fast, inactivating current has been desig. nated $I_{\text {Acd }}$ (Salkoff, 1983), $I_{C}$ (Elkins et al., 1986), $I_{\text {Ac }}$ (Wei and Salkoff, 1986), and $I_{\mathrm{CF}}$ (Singh and $\mathrm{Wu}, 1990$ ). The slow, noninactivating current has been designated $I_{\mathrm{K}_{\mathrm{c}}}$ (Wei and Salkoff, 1986), $I_{\mathrm{c}}$ (Gho and Mallart, 1986), and $I_{\mathrm{CS}}$ (Singh and $\mathrm{Wu}, 1990$ ). We adopt the nomenclature of Singh and $\mathrm{Wu}(1990)$, chosen to maintain consistency with conventional names in other species, that is, $I_{C F}$ for the fast, and $I_{C S}$ for the slow $\mathrm{Ca}^{2 t}$. activated $\mathrm{K}^{+}$current.

\section{Fly stocks}

The wild-type Drosophila melanogaster strain Oregon $\mathrm{R}$ was used. A mutant strain [foreclosed $\left(f_{c}{ }^{244 b}\right)$ ], which fails to close dorsally and has a weak cuticle, was used to facilitate study of late embryonic stages when a tough wild-type cuticle makes dissection difficult. However, in all cases, experiments with the mutant werc confirmed using dissected and/ or cultured wild-type Oregon R embryos.

A mutant allele of the Shaker locus, $S h^{\mathrm{kst} 33}$, was used to eliminate the $I_{\mathrm{A}}$ current (Jan et al., 1977; Salkoff and Wyman, 1981; Wu and Haugland, 1985). The only available allele of the slowpoke (slo) locus was used to eliminate the $I_{\mathrm{CF}}$ current (Elkins et al., 1986; Elkins and Ganetzky, 1988). An Sh;slo double mutant, courtesy of Dr. Chun-Fang $\mathrm{Wu}$ (Singh and $\mathrm{Wu}, 1990$ ), was used to eliminate both $I_{\mathrm{A}}$ and $I_{\mathrm{CF}}$. Neither mutation causes a detectable alteration in any other current in the mature larval muscles (Singh and Wu, 1990). We found that this specificity was also true in the developing embryonic muscle (Table 1).

\section{Preparation}

Breeding flies were maintained on apple juice agar plates at $25^{\circ} \mathrm{C}$ and allowed to lay eggs overnight. The eggs were collected, dechorionated in commercial bleach, and placed in a plastic culture dish for staging. Embryos staged by morphological criteria (Campos-Ortega and Hartenstein, 1985; K. S. Broadie, unpublished observations) to a narrow well-defined developmental time window-usually between the first and second constrictions of the developing gut, a period of $<10 \mathrm{~min}$ at $25^{\circ} \mathrm{C}$ - were selected and allowed to continue development to the desired stage. All development times are reported in hours after egg laying (AEL) at $25^{\circ} \mathrm{C}$ and are recorded as decimals. Under these conditions, embryogenesis lasts $21 \pm 1 \mathrm{hr}$

All experiments were performed on dissected whole-embryo preparations. Younger embryos ( $<17 \mathrm{hr} \mathrm{AEL}$ ) were transferred to polylysinecoated coverslips under normal saline, removed from the vitelline membrane, cut along the dorsal midline with a glass electrode, and attached to the coverslip surface with a gentle stream of saline. Older embryos $(>17 \mathrm{hr})$ were transferred to coverslips coated with a thin layer of Sylgard under normal saline, cut along the dorsal midline with a finc metal blade, and pinned to the Sylgard with glass pins. The gut was then removed exposing the ventral nervous system, peripheral nerves, and somatic musculature. All experiments were performed on the large ventral internal-longitudinal muscle (muscle 6; Crossley, 1978) in anterior abdominal segments A2-A4. 


\section{Whole embryo culture and recording solutions}

The late embryo ( $>17 \mathrm{hr}$ AEL) has a tough cuticle that makes dissection and at tachment to conventional substrates difficult. $\Lambda$ s a result, we have cultured dissected whole embryos from earlier, more amenable stages. Embryos were dissected at $16 \mathrm{hr}$ AEL (as above) and cultured in a small drop (20 $\mu$ ) of modified M3 (MM3) medium (Shields and Sang, 1977; Currie et al., 1988) in a humid chamber at $25^{\circ} \mathrm{C}$. The MM3 culturing medium was similar to previous published reports with the following exceptions/additions: (1) the glutamate salts were replaced with equimolar aspartate salts, (2) $0.125 \mathrm{IU} / \mathrm{ml}$ insulin (Sigma) was added, and (3) $2 \%$ fetal calf serum (Sigma), filtered but not heat inactivated, was added. Under these conditions, the embryo preparations appeared to develop normally as judged by all available morphological, immunohistological, and physiological criteria, with the exception that the trachea fails to fill with air. Experiments with cultured preparations were independently confirmed with freshly dissected embryos.

Physiological recordings were performed with normal fly salines. The bath consisted of (in mmol/liter) $135 \mathrm{NaCl}, 5 \mathrm{KCl}, 4 \mathrm{MgCl}_{2}, 2 \mathrm{CaCl}_{2}$, 5 TES (N-tris[hydroxymethyl]methyl-2-aminoethane sulfonic acid), and 36 sucrose. The calcium concentration was varied as indicated in the figure captions: a calcium-free bath was prepared by removal of $\mathrm{CaCl}_{2}$ and addition of $14 \mathrm{mM} \mathrm{MgCl}_{2}$ and $0.5 \mathrm{mM}$ EGTA; a high-calcium solution was prepared with $20 \mathrm{mM} \mathrm{CaCl}$. The intracellular solution consisted of (in mmol/liter) $120 \mathrm{KCl}, 20 \mathrm{KOH}, 4 \mathrm{MgCl}_{2}, 5 \mathrm{TES}, 5$ EGTA, $0.25 \mathrm{CaCl}_{3}, 4 \mathrm{ATP}, 4 \mathrm{GTP}$, and 36 sucrose. To study calcium currents, $\mathrm{KCl}$ was replaced with $\mathrm{CsCl}$ as indicated in the figure captions. The $\mathrm{pH}$ of all solutions was buffered at 7.15 .

\section{Isolation of ionic currents}

The whole-cell voltage-gated current is composed of an inward calcium current $\left(I_{\mathrm{C}_{\mathrm{a}}}\right)$ and four outward potassium currents (Fig. 1); two fast, inactivating currents, voltage gated $\left(I_{\mathrm{A}}\right)$ and calcium dependent $\left(I_{\mathrm{CF}}\right)$; and two delayed, noninactivating currents, voltage gated $\left(I_{K}\right)$ and calcium dependent $\left(I_{C S}\right)$. In these experiments, we have used mutations and ion substitutions to dissect these currents from the whole-cell response during voltage clamp.

Calcium current $\left(\mathbf{I}_{(a)}\right)$. CsCl was substituted for $\mathrm{KCl}$ in the patch pipette. Intracellular $\mathrm{K}^{+}$was replaced with $\mathrm{Cs}^{+}$via perfusion in wholecell configuration for $5 \mathrm{~min}$. In this configuration, no outward $\mathrm{K}$ ' currents could be recorded in a $\mathrm{Ca}^{2+}$-free bath. Thus, the inward $l_{\mathrm{Ca}}$ could be recorded in the absence of all four outward potassium currents.

Rapid, voltage-gated potassium current $\left(\mathrm{I}_{t}\right)$. External calcium was removed (see above), eliminating both the inward calcium current and the calcium-dependent potassium currents, $I_{\mathrm{C} \cdot \mathrm{F}}$ and $I_{\mathrm{CS}} . I_{\mathrm{A}}$ and $I_{\mathrm{K}}$ can be temporally separated. Alternatively, $I_{\mathrm{A}}$ can be specifically eliminated in $S h^{\mathrm{K} \$ 133}$ mutants and $I_{\mathrm{A}}$ amplitude obtained by subtraction (wild-type - $S h$ ). There was no significant difference in $I_{\mathrm{A}}$ amplitude assayed with the two methods; the first method was routinely used.

Rapid, calcium-dependent potassium current $\left(\mathrm{I}_{(F)}\right)$. Sh $h^{\mathrm{KS} 133}$ was used to eliminate $I_{\mathrm{A}} . I_{\mathrm{CF}}$ can be temporally separated from the delayed currents $\left(I_{\mathrm{K}}, I_{\mathrm{C}}\right) ; I_{\mathrm{C}}$ must be subtracted. Alternatively, $I_{\mathrm{CF}}$ can be specifically eliminated using the slo mutation and $I_{\mathrm{CF}}$ amplitude obtained by subtraction (wild-type - slo). There was no significant difference in $I_{C F}$ amplitude assayed with the two methods; the first method was routinely used.

Delayed, voltage-gated potassium current $\left(\mathrm{I}_{K}\right) \cdot S h^{\mathrm{K} 133}$ was used to eliminate $I_{\mathrm{A}}$. External calcium was removed, eliminating both the inward calcium current and both calcium-dependent potassium currents $\left(I_{\mathrm{CF}}, I_{\mathrm{CS}}\right)$. In this configuration, $I_{\mathrm{K}}$ can be studied in isolation.

Delayed, calcium-dependent potassium current $\left(\mathrm{I}_{\mathrm{C} S \mathrm{~s}}\right)$. An Sh;slodouble mutant was used to climinate $I_{\mathrm{A}}$ and $I_{\mathrm{C}}$, respectively. $I_{\mathrm{CS}}$ was obtained by subtracting $I_{\mathrm{K}}$ and $I_{\mathrm{a}, \mathrm{a}}$, both of which can be studied in isolation.

In these experiments, only $I_{\mathrm{K}}$ and $I_{\mathrm{C}_{\mathrm{a}}}$ could be studied directly in the absence of all other ionic currents. $I_{\mathrm{A}}$ could be studied in the presence of only the delayed $I_{\mathrm{K}}$, which can be temporally resolved from the $I_{\mathrm{A}}$ peak. Values for $I_{\mathrm{CF}}$ and $I_{\mathrm{CS}}$ were obtained only from multiple current traces; $I_{\mathrm{F}}$ can be specifically eliminated $(s l o)$, but $I_{\mathrm{CS}}$ can be measured only in recordings in which the other current components were identified and subtracted as detailed above.

\section{L-Glutamate iontophoresis}

The glutamate-gated current at the developing neuromuscular junction (NMJ) was studied by L-glutamate iontophoresis. A stock solution of $0.1 \mathrm{M}$ L-glutamate (monosodium salt; Sigma) of $\mathrm{pH} 8$ was made fresh
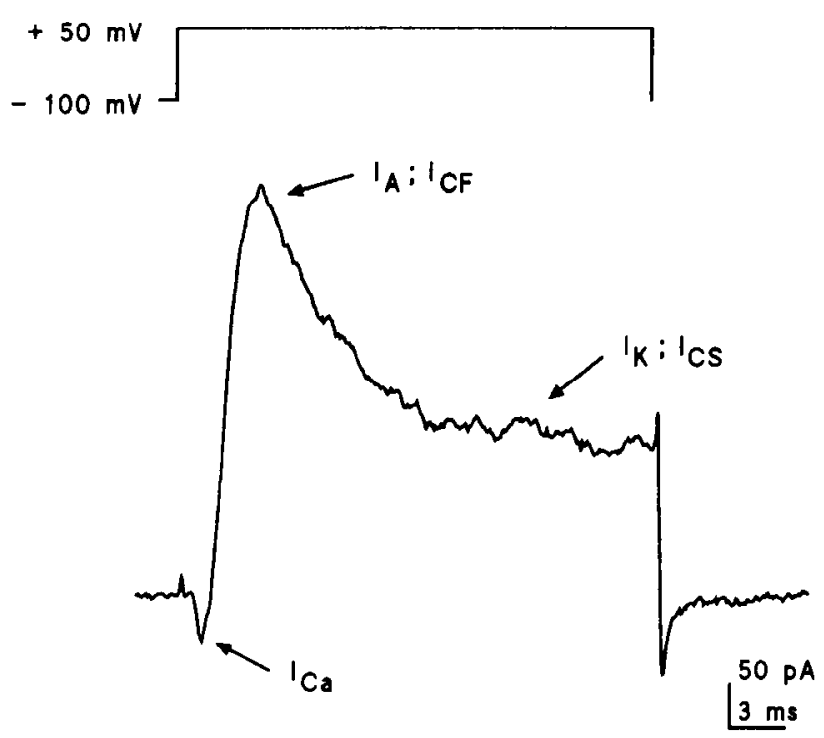

Figure 1. The whole-cell voltage-gated currents in the late embryonic myotube $6(20 \mathrm{hr}$ AEL). Five currents underlie the whole-cell response to a voltage step $(-100$ to $+50 \mathrm{mV})$, an inward calcium current $\left(I_{\mathrm{ca}}\right)$ and four outward potassium currents: two fast currents, voltage gated $\left(I_{A}\right)$ and calcium dependent $\left(I_{C F}\right)$; and two delayed currents, voltage gated $\left(I_{\mathrm{K}}\right)$ and calcium dependent $\left(I_{\odot \mathrm{S}}\right)$. The fast and slow $\mathrm{K}^{+}$currents have different activation rates and can be temporally separated. The fast $\mathrm{K}+$ currents $\left(I_{\mathrm{A}}, I_{\mathrm{CF}}\right)$ rapidly inactivatc and so do not contribute to the noninactivating current response, composed of the outward $I_{\mathrm{K}}$ and $I_{\ulcorner\mathrm{S}}$ and the inward $I_{\mathrm{Ca}}$. The inward $\mathrm{Ca}^{2+}$ current is largely masked by the outward $\mathrm{K}^{+}$currents.

daily. Iontophoretic pipettes were pulled with resistances of 50-75 M 2 . Glutamate was iontophoresed with short pulses $(<1 \mathrm{msec})$ of negative current (10 nA; Farnell pulse-generating system) at the developing NM J zone (preceding companion article, Broadie and Bate, 1992). Glutamate leakage between pulses was prevented with a small, positive backing current.

\section{Electrophysiology: whole-cell patch-clamp techniques}

For physiological experiments, the preparation was placed in a small perspex recording chamber and viewed in transmitted light with a compound microscope (Micro Instruments Ltd.) fitted with differential interference contrast (Nomarski) optics and a $40 \times$ water-immersion lens. Whole-cell recordings were made at room temperature $\left(18-22^{\circ} \mathrm{C}\right)$ with patch pipettes pulled (Narishige patch-electrode puller) from borosilicate glass (fiber filled) with tips fire polished to final resistances of 5-8 $\mathrm{M} \Omega$. Whole-cell recordings were achieved using standard patch-clamp techniques (Hamill et al., 1981; Marty and Neher, 1983). Signals were amplified using an Axopatch-1D (Axon Instruments) patch-clamp amplifier, filtered with an 8-pole Bessel filter at $2 \mathrm{KHz}$, and either sampled on line or digitally stored on a modified digital audio tape recorder (Sony) for later analysis. Data were analyzed using pCLAMP version 5.51 software (Axon Instruments) on a Viglen III/33 MHz computer.

Seal resistances were typically $>10 \mathrm{G} \Omega$. Whole-cell configuration was achieved easily with slight suction, and input resistance of the myotube was in the range of 200-500 M . With maximum currents less than 1 $\mathrm{nA}$, series resistance errors (total current $\times$ series resistance) are kept to reasonable levels (usually $<10 \mathrm{mV}$ ) and were not corrected. Myotubes with these characteristics, average diameter of $12 \mu \mathrm{m}$, and average length of $36 \mu \mathrm{m}$, should show reasonable space clamp. Series resistances were taken from the series resistance control on the amplifier and monitored throughout the experiment; typical values ranged from 10 to $25 \mathrm{M} \Omega$. Cell capacitances were between 7 and $14 \mathrm{pF}$, increasing with developIIIental age, generating clamp time constants $\left(R_{\text {series }} \times C_{\text {cell }}\right)$ averaging less than $0.25 \mathrm{msec}$. Though cell capacitance increased with developmental age, the size of the cell was not significantly increased. We hypothesize that this capacitance increase arises rather through the elaboration of the muscle tracheole system during late embryogenesis or some other changes in membrane properties. Because of this uncer- 


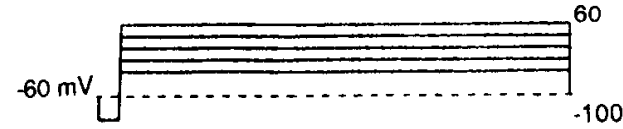

\section{$13.25 \mathrm{hrs}$}

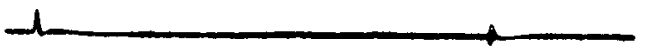

$14 \mathrm{hrs}$

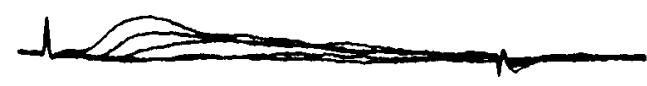

$18 \mathrm{hrs}$

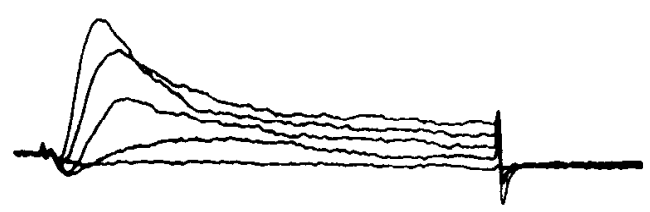

21 hrs
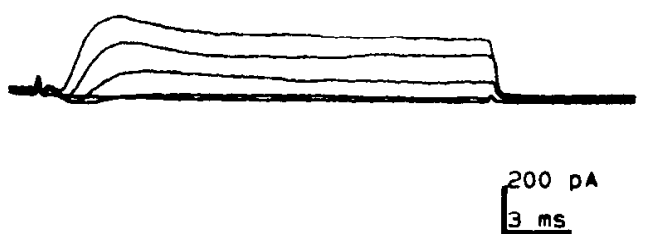

Figure 2. Development of the whole-cell voltage-gated currents in the embryonic myotube 6 . At the earliest time point (13.25 hr AEL), immediately after the myotubes uncouple, no net current response is observed. Whole-cell currents appear soon thereafter (14 hr AEL), reach a peak in the late embryo ( $18 \mathrm{hr}$ AEL), and decline prior to hatching $\left(21 \mathrm{hr}\right.$ AEL). The outward $\mathrm{K}^{+}$currents largely mask the inward $\mathrm{Ca}^{2+}$ current, which is therefore difficult to discern, especially during early development. The myotubes are voltage clamped at $-60 \mathrm{mV}$; a $2 \mathrm{sec}$, $-100 \mathrm{mV}$ prepulse precedes the voltage step to eliminate inactivation. Superimposed traces show voltage steps to $-20,0,20,40$, and $60 \mathrm{mV}$. Each trace is the average of five trials.

tainty, current amplitude rather than current density is displayed in voltage-clamp recordings.

Two voltage-clamp protocols were used routinely to monitor voltagegated currents: (1) an activation protocol that involved a $2 \mathrm{sec}$ prepulse at $-100 \mathrm{mV}$, to remove inactivation, and a voltage step to increasingly positive values in $20 \mathrm{mV}$ increments; on-line leak subtraction was routinely used; and (2) a steady-state inactivation protocol that involved a $2 \mathrm{sec}$ prepulse starting at $0 \mathrm{mV}$ and decreasing in $20 \mathrm{mV}$ increments, and a voltage step to a constant $+60 \mathrm{mV}$. No leak subtraction was employed in this configuration.

\section{Results}

The embryonic musculature and development of muscular activity

Each hemisegment of the Drosophila embryo (A2-A7) has 30 syncytial muscle fibers innervated by two peripheral nerves: the anterior intersegmental nerve, which innervates the dorsal mus- culature, and the posterior segmental nerve, which innervates the ventral muscles. In this developmental analysis, we have focused on a single identifiable muscle fiber: the large, ventral, internal-longitudinal muscle (muscle 6; Crossley, 1978) in anterior abdominal segments A2-A4. This muscle has been characterized physiologically and morphologically in the larva (Jan and Jan, 1976a,b; Singh and $\mathrm{Wu}, 1990$ ) and morphologically examined in the embryo (Bate, 1990), and its size and position make it the most amenable muscle for embryonic manipulation.

Previous studics (Batc, 1990) have cxamined the origin and time course of early myogenic events in the Drosophila embryo. The embryonic myotubes arise through the fusion of mesodermal myoblasts during the second quarter of embryogenesis, followed by the establishment of epidermal insertion sites prior to dorsal closure (Bate, 1990). By $13 \mathrm{hr}$ AEL, at the completion of dorsal closure (early stage 16), the mature muscle pattern is complete, but the muscles remain quiescent and are noncontractile when electrically stimulated or challenged with L-glutamate, the neurotransmitter at the NMJ. By $13.5 \mathrm{hr}$ AEL, the myotube will contract when electrically stimulated, and endogenous contractions begin soon after (13.75-14 hr AEL). In the following period, endogenous muscle contractions increase gradually in frequency; initially only isolated myotubes contract, but by $14.5 \mathrm{hr}$ AEL, coordinated, peristaltic contractions of entire hemisegments begin. At $16 \mathrm{hr}$ AEL, an abrupt acceleration of peristaltic muscle contractions begins, and frequent muscle contractions, characteristic of larval locomotory movements, persist through the end of embryogenesis.

As in vertebrates (Dennis et al., 1981), the myotubes of Drosophila are electrically and dye coupled through much of their embryonic development (Johansen et al., 1989; Broadie and Bate, 1992), allowing the spread of depolarization laterally between fibers. Between 13-13.25 hr AEL, the myotubes abruptly uncouple (Broadie and Bate, 1992), immediately prior to the rapid maturation of muscular activity. We note that this abrupt uncoupling closely correlates with the initial stages of electrogenic development.

\section{Development of whole-cell currents}

As in the third instar larva, the muscles of the mature Drosophila embryo have five prominent voltage-gated extrajunctional ionic currents (Fig. 1): an inward calcium current and four outward potassium currents. When viewed in whole-cell configuration, these five components interact to generate a complex current response to a controlled voltage change. It is possible to follow the evolution of this response throughout myogenesis in the Drosophila embryo (Fig. 2). In the immature embryonic myotubes, prior to dorsal closure (stage $16,<13 \mathrm{hr}$ AEL), the myotubc membranc contains no voltage-gated channels as assayed in cell-attached patches (no activity in 25 patches) and the myotube appears electrically inert. When whole-cell voltageclamp becomes feasible, after the myotubes abruptly uncouple (13-13.25 hr AEL), no whole-cell current is generated in response to voltage changes (Fig. 2). However, electrogenesis of voltage-gated currents begins soon thereafter (by $13.5 \mathrm{hr}$ AEL). Initially (13.25-13.5 hr AEL), this activity is restricted to singlechannel openings in response to a voltage step in cell-attached patches. During this period, we also observe for the first time the prominent stretch-activated $\mathrm{K}^{+}$currents identified by earlier workers (Aldrich et al., 1989; data not shown), but no quantitative assay was undertaken.

Whole-cell voltage-gated currents can first be recorded at 13.5 $\mathrm{hr}$ AEL. The initial whole-cell current has an activation thresh- 


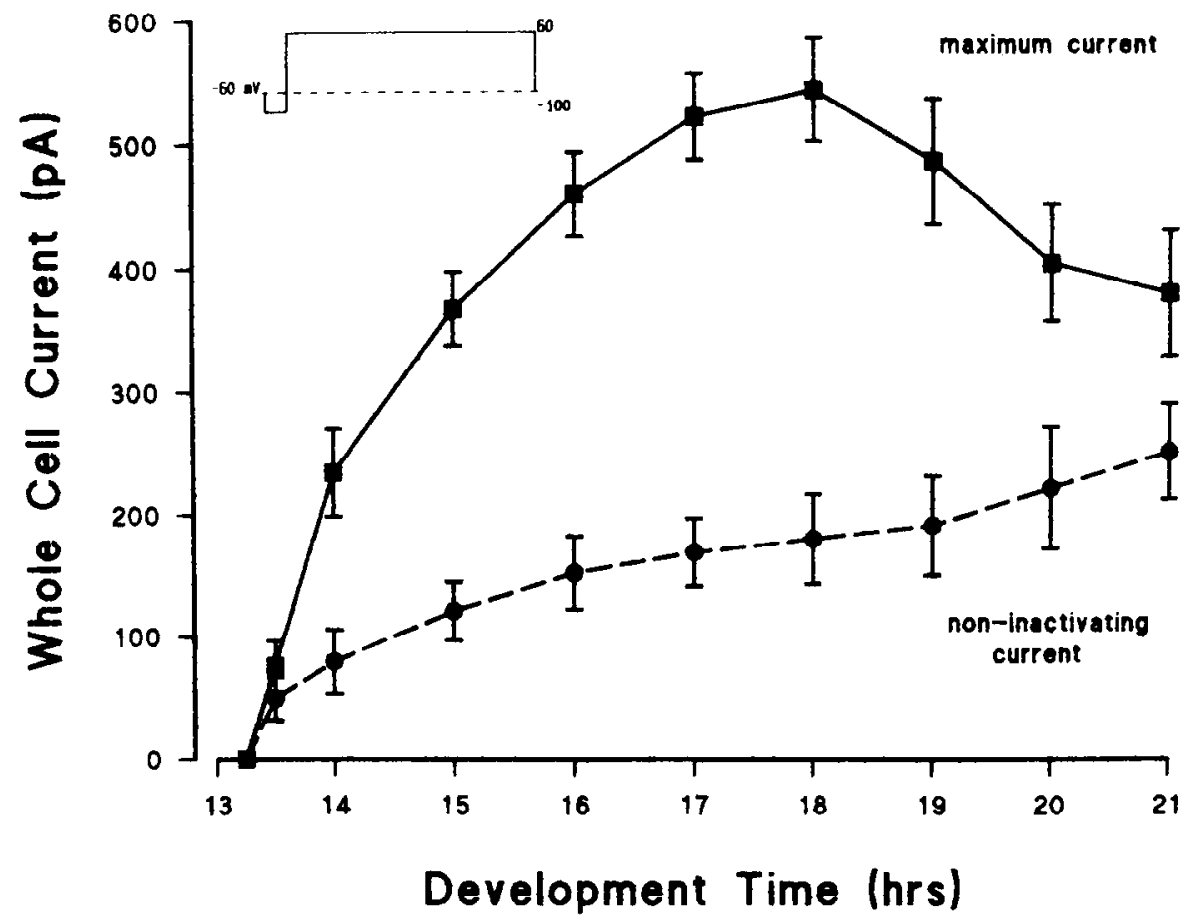

Figure 3. Development of the wholecell voltage-gated current in the embryonic myotube 6. Maximum current represents peak current amplitudes; noninactivating current represents current amplitude $50 \mathrm{msec}$ after voltage step. Both components appear concurrently at 13.25-13.5 hr AEL, immediately after myotube uncoupling. The noninactivating component increases gradually throughout late embryogenesis; the inactivating component increases more rapidly, peaks in the late embryo ( $18 \mathrm{hr} \mathrm{AEL}$ ), and declines prior to hatching ( $21 \mathrm{hr}$ AEL). The current is measured in response to a voltage step from a $-100 \mathrm{mV}$ prepulse $(2 \mathrm{sec})$ to $+60 \mathrm{mV}$. Each point shows the mean \pm SD for at least 10 embryos $(N-10)$. old of $0 \mathrm{mV}$ and a maximum amplitude less than $100 \mathrm{pA}(+60$ $\mathrm{mV}$; Fig. 2). From the earliest stages, three components of the current can be discerned: (1) an initial small, inward current; (2) a rapid, fast-inactivating outward current; and (3) a noninactivating outward current that persists for the length of the voltage step. All three components of the whole-cell current appear concurrently at 13.5-13.75 hr AEL (Figs. 2, 3). The inward component is often difficult to discern, as it is concealed by the opposing outward currents.

The whole-cell current rapidly matures over the next several hours (14-18 hr AEL; Figs. 2, 3). A continuous increase is observed in both the inward current and the inactivating and noninactivating components of the outward currents. Similarly, the inward current and noninactivating outward current continue to increase gradually for the remainder of embryogenesis (Figs. $2,3)$. However, the developmental profile of the inactivating outward current is strikingly different (Figs. 2,3 ): it initially (14$18 \mathrm{hr}$ AEL) develops more rapidly, peaks (18 hr AEL), and declines markedly prior to hatching ( $21 \mathrm{hr}$ AEL). The net effect is a whole-cell current profile that changes dynamically throughout late myogenesis.

\section{Development of the rapid, inactivating potassium currents}

From analysis of larval stages (Singh and Wu, 1990), it is known that the rapid, inactivating outward current is composed of two potassium currents: voltage gated $\left(I_{\mathrm{A}}\right)$ and calcium dependent $\left(I_{\mathrm{CF}}\right)$. These currents are carried through two channels encoded by the Shaker locus $\left(I_{\mathrm{A}}\right)$ and slo locus $\left(I_{\mathrm{CF}}\right)$, respectively. $\mathrm{Mu}$ tations exist in both these structural genes that allow the selective elimination of the contribution of their gene products from the whole-cell current. We have exploited these tools to dissect the developmental profile of both $I_{\mathrm{A}}$ and $I_{\mathrm{CF}}$.

It is casicst to study $I_{\mathrm{A}}$ development in a calcium-free extracellular bath, which eliminates the calcium current and the $\mathrm{Ca}^{2+}$ dependent $\mathrm{K}^{+}$currents - specifically, for our purposes, the rapid $I_{\mathrm{CF}}$ (Fig. 4). This protocol leaves only the voltage-gated $I_{\mathrm{A}}$ and $I_{\mathrm{K}}$ intact, which can be temporally distinguished. Alternatively, the value of $I_{\mathrm{A}}$ can be obtained by subtracting the $I_{\mathrm{K}}$ component that can be studied in isolation (see below). As previously reported in the mature larval muscle (Singh and $\mathrm{Wu}, 1990$ ), $I_{\mathrm{A}}$ in the embryo is rapidly activated and inactivated by membrane depolarization; inactivation is essentially complete $50 \mathrm{msec}$ after a voltage step to $60 \mathrm{mV}$, with remaining current negligible ( $<2 \%$ peak amplitude). As in cultured myotubes (Zagotta et al., 1989 ), we find that $I_{\mathrm{A}}$ activity diminishes rapidly in whole-cell recordings, possibly as the result of a long-lived inactivation state. $I_{\mathrm{A}}$ amplitude has usually decreased by $50 \%$ within $5 \mathrm{~min}$ of attaining whole-cell configuration (data not shown), though this rundown phenomenon is highly variable and seems strongly use dependent. To maximize consistency, recordings were made within $2 \mathrm{~min}$ of establishing whole-cell configuration.

$I_{\mathrm{A}}$ current can first be detected at 13.5-13.75 hr AEL (see Figs. 4,7 ), soon after myotube uncoupling. Initially, $I_{\mathrm{A}}$ amplitude is small ( $<25 \mathrm{pA}$ peak; $-100 /+60 \mathrm{mV}$ voltage step), but it rapidly increases over the next several hours (14-18 hr AEL; see Figs. 4, 7), and by $18 \mathrm{hr}$ AEL, a prominent current (480 \pm $34 \mathrm{pA})$ is present. Throughout this period, $I_{\mathrm{A}}$ accounts for all the inactivating outward current; a null Shaker mutant ( $\left.S h^{\mathrm{kS1} 33}\right)$ eliminates all the inactivating outward current in both normal and calcium-free salines (Fig. 4). At $18 \mathrm{hr}$ AEL (see Figs. 4, 7), the $I_{\mathrm{A}}$ current peaks and a sharp decline in $I_{\mathrm{A}}$ amplitude $(31 \pm$ $12 \%$ ) occurs in the last hours of embryogenesis prior to hatching (21 hr AEL). The mechanism of this rapid decline is unknown.

$I_{\mathrm{CF}}$ development was assayed in the $S h^{\mathrm{ks} / 33}$ mutant, which completely eliminates the dominant $I_{\mathrm{A}}$ current in the embryonic myotubes (Fig. 4). $I_{C F}$ can be temporally resolved from the delayed outward currents $\left(I_{\mathrm{K}}\right.$ and $\left.I_{\mathrm{CS}}\right)$. However, $I_{\mathrm{CF}}$ is a calciumdependent current and must be preceded by a large calcium influx for its activation; therefore, $I_{\mathrm{Ca}}$ is a necessary contamination and must be subtracted to obtain $I_{\mathrm{CF}}$ amplitude (see below). The EGTA Ca ${ }^{2+}$ buffer in the intracellular pipette had no significant influence on the appearance or amplitude of $I_{\mathrm{CF}}$ As reported in the larva (Gho and Mallart, 1986), $I_{C F}$ in the embryonic myotubes, like $I_{\mathrm{A}}$, is rapidly inactivated by membrane depolarization, with a time course very similar to $I_{\mathrm{A}}$.

Unlike $I_{\mathrm{A}}, I_{\mathrm{CF}}$ is not present during the initial stages of elec- 


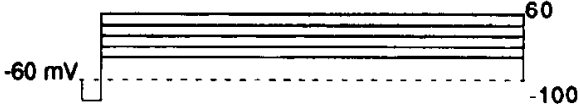

$14 \mathrm{hrs} \quad 0 \mathrm{mM} \mathrm{Ca}{ }^{++}$

Figure 4. Development of the fast potassium currents, $I_{\mathrm{A}}$ and $I_{\mathrm{CF}}$. In the first column, calcium is removed from the extracellular medium to abolish the inward calcium current $\left(I_{\mathrm{C}_{\mathrm{C}}}\right)$ and the calcium-dependent potassium currents $\left(I_{C \mathrm{~F}}\right.$ and $\left.I_{C S}\right)$. Only the voltage-gated potassium currents $\left(I_{\mathrm{A}}\right.$ and $\left.I_{\mathrm{K}}\right)$ remain, which can be temporally resolved. In the second column, a Shaker mutant ( $\left.S h^{\mathrm{KS} 133}\right)$ abolishes $I_{\mathrm{A}}$, and high external calcium ( $20 \mathrm{~mm}$ ) is used to emphasize the fast, calcium-dependent potassium current $\left(I_{\mathrm{CF}}\right)$. The delayed currents, $I_{\mathrm{K}}$ and $I_{\mathrm{CS}}$, remain but can be temporally resolved from the rapid $I_{\mathrm{CF}}$. $I_{\mathrm{A}}$ appears early in development (by $14 \mathrm{hr} \mathrm{AEL),} \mathrm{peaks} \mathrm{(18}$ hr AEL), and declines before hatching (21 hr AEL). $I_{\mathrm{CF}}$ is absent for most of embryogenesis, appearing late in development (18 hr AEL) and increasing slowly until hatching. The myotubes are voltage clamped at $-60 \mathrm{mV}$; a $2 \mathrm{sec}$, $-100 \mathrm{mV}$ prepulse precedes the voltage step to eliminate inactivation. Superimposed traces show voltage steps to $-20,0,20,40$ and $60 \mathrm{mV}$. Each trace is the average of five trials.

\section{$16 \mathrm{hrs}$}
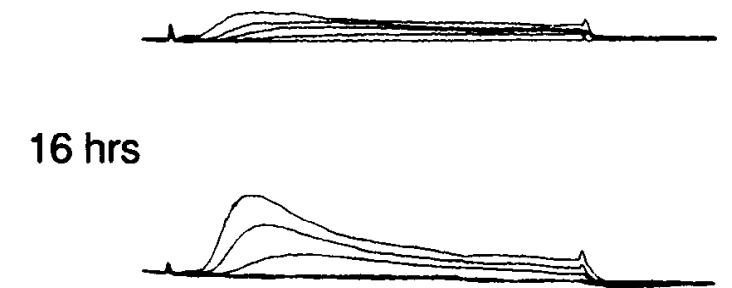

$18 \mathrm{hrs}$

\section{$21 \mathrm{hrs}$}

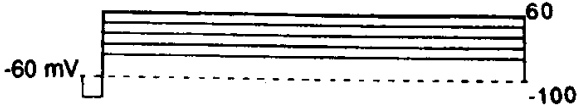

$\mathrm{Sh}\left(20 \mathrm{mM} \mathrm{Ca}{ }^{++}\right)$
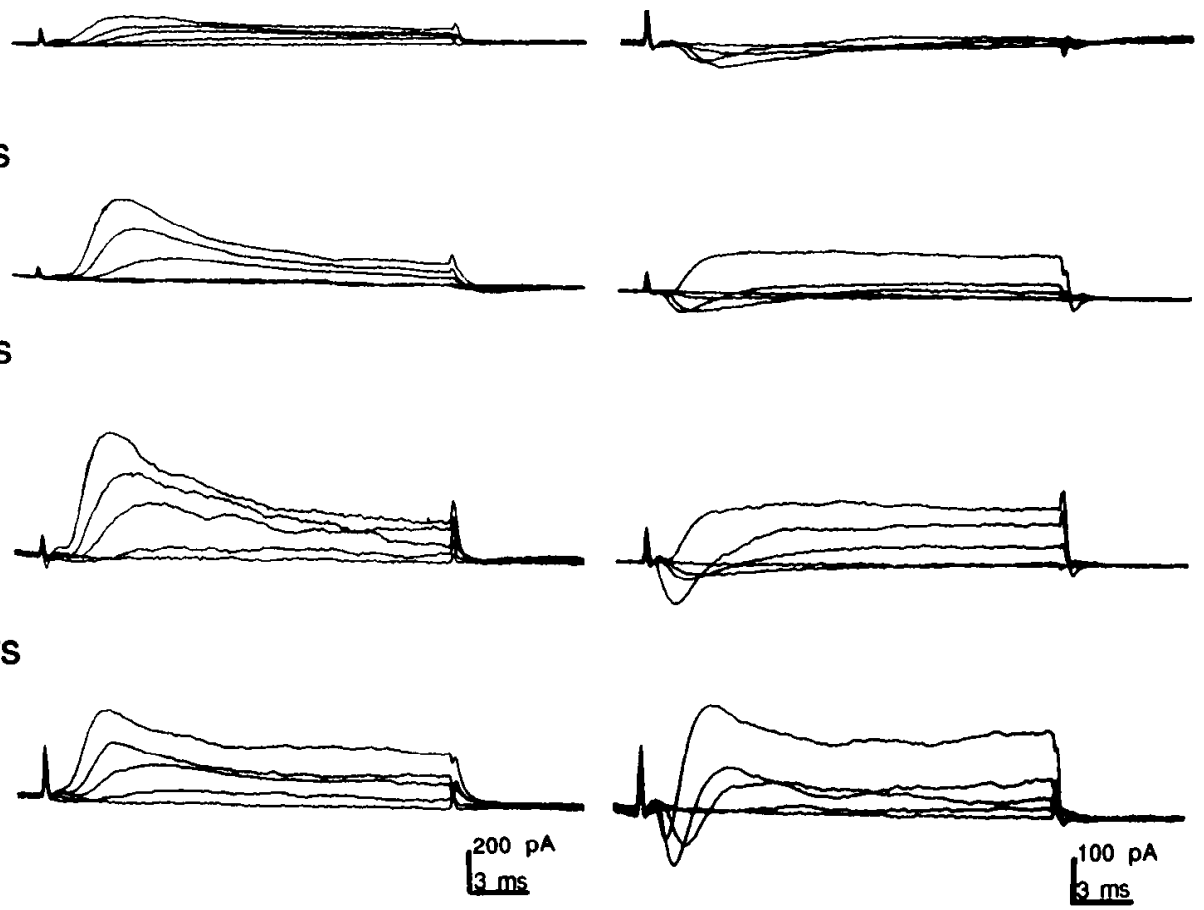

trogenesis (13.5-17 hr AEL) and plays no role in myotube physiology for most of embryogenesis (see Figs. 4, 7). $I_{\mathrm{CF}}$ current is first observed at $17-17.5 \mathrm{hr}$ AEL. The initial current has a very low amplitude ( $<25 \mathrm{pA}$ peak; $-100 /+60 \mathrm{mV}$ voltage step) and appears negligible compared to the $I_{\mathrm{A}}$ current ( $>400 \mathrm{pA}$ peak) at this time (see Figs. 4, 7). Again, unlike $I_{\mathrm{A}}$, the amplitude only increases gradually after this initial appearance, and at hatching $\left(21 \mathrm{hr}\right.$ AEL) $I_{C F}$ has a peak amplitude $<100 \mathrm{pA}$ (see Figs. 4,7 ). Though $I_{\mathrm{A}}$ has declined in the interim (18-21 hr AEL), $I_{\mathrm{A}}$ amplitude at hatching is still many times greater than $I_{\mathrm{CF}}$ amplitude.

\section{Development of the delayed potassium currents}

From the larval stages, it is known that the delayed, inactivating component of the outward current is composed of two potassium currents: voltage gated $\left(I_{\mathrm{K}}\right)$ and calcium dependent $\left(I_{\mathrm{CS}}\right)$. Unlike the rapid, inactivating currents $\left(I_{\mathrm{A}}, I_{\mathrm{CF}}\right)$, these currents have not been characterized at a genetic level and no mutations are known that eliminate them specifically. Nevertheless, owing to their delayed onset relative to the fast currents, and owing to the rapid inactivation of the fast currents, it is possible to isolate these two components temporally. We found that both $I_{\mathrm{A}}$ and $I_{\mathrm{CF}}$ inactivated rapidly in the embryonic myotubes. Inactivation was essentially complete $50 \mathrm{msec}$ after the voltage step and the remaining current was negligible or absent. On the other hand, $I_{\mathrm{K}}$ and $I_{\mathrm{CS}}$ reached a peak amplitude by $50 \mathrm{msec}$ after the voltage step and did not inactivate even after a prolonged period $(500 \mathrm{msec})$. The delayed currents themselves are differentiated on the basis of calcium dependency.

It is easiest to examine $I_{\mathrm{K}}$ in a calcium-free bath, which eliminates the calcium current and both calcium-dependent $\mathrm{K}^{+}$cur- rents. If a Shaker mutant $\left(S h^{\mathrm{KS} / 33}\right)$ is used to eliminate $I_{\wedge}, I_{\mathrm{K}}$ can be examined in isolation (Fig. 5). $I_{\mathrm{K}}$ appears soon after myotube uncoupling (13.15-13.25 hr AEL), early in electrogenesis and concurrent with the appearance of $I_{\mathrm{A}}$ (see Fig. 7). Initially (13.5-14 $\mathrm{hr} \mathrm{AEL}), I_{\mathrm{K}}$ amplitude increases rapidly, though more slowly than $I_{\mathrm{A}}$, such that $I_{\mathrm{A}}$ amplitude soon becomes several times greater than $I_{\mathrm{K}}(16 \mathrm{hr}$ AEL; see Fig. 7). During late development ( $>15 \mathrm{hr}$ AEL; see Figs. 5, 7), $I_{K}$ increases much more gradually, increasing continuously through the end of embryogenesis. There is no indication of a late decline in $I_{\mathrm{K}}$ amplitude, which appears to be an exclusive characteristic of $I_{\mathrm{A}}$. At hatching (21 hr AEL; see Fig. 7), $I_{K}$ has a whole-cell amplitude $>200 \mathrm{pA}\left(-100 /+60 \mathrm{mV}\right.$ voltage step), nearly as large as $I_{\mathrm{A}}$ and second only to $I_{\mathrm{A}}$ among the myotube voltage-gated currents.

As in the larva (Singh and $\mathrm{Wu}, 1990$ ), quinidine blocks $I_{\mathrm{K}}$ in the embryonic myotubes. In $\mathrm{Ca}^{2+}$-free saline, quinidine at 10 $\mu \mathrm{mol} /$ liter reduced $I_{\mathrm{K}}$ amplitude by up to $50 \%$ but did not significantly alter $I_{\mathrm{A}}$ (data not shown). On the other hand, quinidine at $1 \mathrm{mmol} /$ liter still left considerable $I_{\mathrm{K}}$ current (up to $30 \%$ ) and we were never able to block $I_{\mathrm{K}}$ completely. This may indicate subpopulations of $I_{\mathrm{K}}$ with differing sensitivity to quinidineblockade or a complex blocking mechanism. As a consequence of this uncertainty, we never used quinidine block to estimate $I_{\mathrm{K}}$ amplitude or to eliminate the $I_{\mathrm{K}}$ component from multicurrent recordings.

$I_{\mathrm{CS}}$ is difficult to examine. The noninactivating component of the whole cell can be measured with and without external $\mathrm{Ca}^{2+}$ to determine the $\mathrm{Ca}^{2+}$-dependent $I_{\mathrm{CS}}$ contribution. An $S h ; s l o$ double mutant is used to eliminate all traces of the rapid, in- 


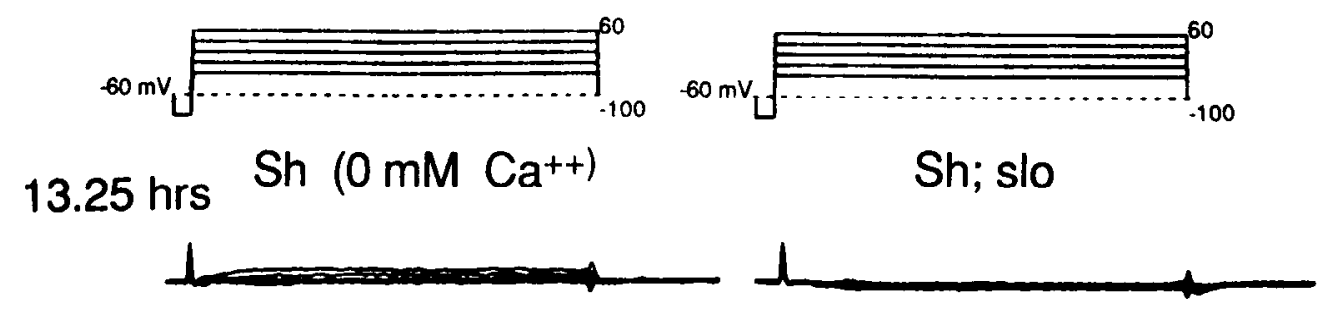

\section{$14 \mathrm{hrs}$}
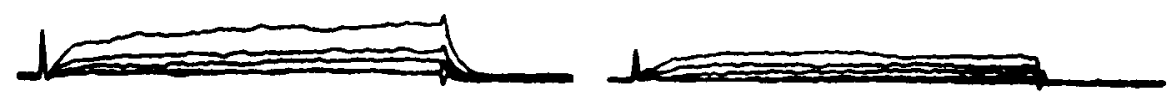

$18 \mathrm{hrs}$
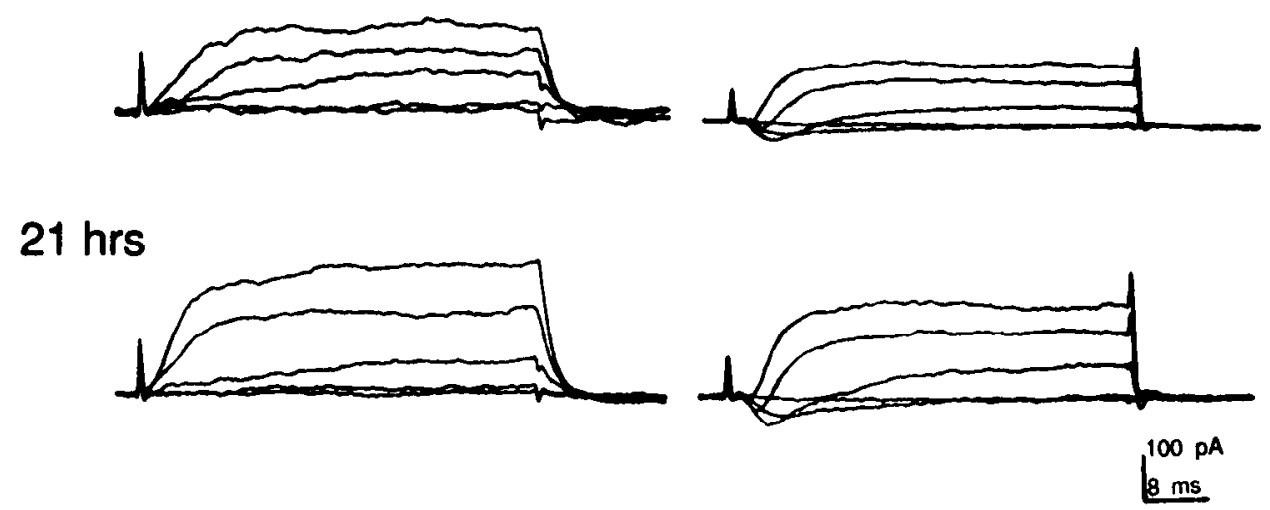

Figure 5. Development of the delayed potassium currents, $I_{\mathrm{K}}$ and $I_{\mathrm{CS}}$. In the first column, a Shaker mutant $\left(S h^{\mathrm{ks} \text { 133 }}\right)$ abolishes $I_{\mathrm{A}}$; removing external calcium (see Materials and Methods) abolishes both the inward calcium current $\left(I_{\mathrm{Ca}}\right)$ and the calcium-dependent potassium currents $\left(I_{\mathrm{CF}}\right.$ and $\left.I_{\mathrm{CS}}\right)$. Hence, $I_{\mathrm{K}}$ can be followed in isolation. In the second column, an $S h$;slo double mutant eliminates both of the rapid, inactivating currents, $I_{\mathrm{A}}$ and $I_{\mathrm{CF}}$. The remaining noninactivating current represents the sum of the outward $I_{\mathrm{K}}$ and $I_{\mathrm{CS}}$, and the inward $I_{\mathrm{Ca}}\left(2 \mathrm{mM} \mathrm{Ca}{ }^{2+}\right.$ in bath). $I_{\mathrm{CS}}$ amplitude can be obtained by subtracting $I_{\mathrm{K}}$ ( first column) and $I_{\mathrm{Ca}}$ (see below), both of which can be studied in isolation. $I_{\mathrm{K}}$ appears early in development (by $14 \mathrm{hr} \mathrm{AEL}$ ) and increases steadily throughout embryogenesis. $I_{\mathrm{CS}}$ is absent for most of embryogenesis, appearing late in development (18 hr AEL) and increasing slowly until hatching. The myotubes are voltage clamped at $-60 \mathrm{mV}$; a $2 \mathrm{sec},-100 \mathrm{mV}$ prepulse precedes the voltage step to climinate inactivation. Superimposed traces show voltage steps to $-20,0,20,40$, and $60 \mathrm{mV}$. Each trace is the average of five trials.

activating current (Fig. 5), but $I_{\mathrm{K}}, I_{\mathrm{Ca}}$, and $I_{\mathrm{CS}}$ remain, all noninactivating and with similar time courses. Therefore, $I_{\mathrm{CS}}$ development was measured by subtracting the contributions of $I_{\mathrm{K}}$ (Fig. 5) and $I_{\mathrm{Ca}}$ (Fig. 6), both of which can be obtained in isolation. $I_{\mathrm{CS}}$ has a very similar developmental time course to $I_{\mathrm{CF}}$ in that it is absent for most of embryogenesis, appears only late in muscle development, and contributes negligibly to the wholecell current even at hatching (Figs. 5, 7). $I_{\mathrm{CS}}$ appears slightly later than $I_{\mathrm{CF}}$, at $18-18.5 \mathrm{hr}$ AEL (Fig. 7). It has a very low initial amplitude and matures only gradually, such that at hatching it has an amplitude of $<50 \mathrm{pA}(-100 /+60 \mathrm{mV}$ voltage step $)$ and is the smallest of the four outward potassium currents (Figs. $5,7)$.

\section{Development of the inward currents: the calcium current and glutamate-gated synaptic current}

Muscle contraction in the mature larva is mediated by an inward calcium current (Jan and Jan, 1976a,b; Singh and Wu, 1990). Similarly, muscle contraction in the mature embryo can be blocked by calcium channel blockers or in a calcium-free saline. It is possible to block all outward potassium currents by replacing intracellular $\mathrm{K}^{+}$with $\mathrm{Cs}^{+}$in whole-cell configuration (Fig. 6A). In this configuration, an inward, noninactivating cal- cium current can be recorded. In $\mathrm{Ca}^{2+}$-free saline, this current is abolished and no voltage-gated currents are recorded (data not shown), indicating that no other inward currents are present and that blockage of the potassium conductances is essentially complete. In particular, we did not find evidence for an inward sodium current in the embryonic muscle as has been reported in the mature larval muscle (Yamaoka and Ikeda, 1988).

The calcium current $\left(I_{\mathrm{Ca}}\right)$ is the first macroscopic voltage-gated current revealed when the embryonic myotubes uncouple at 1313.25 hr AEL (Fig. 7). Indeed, a large calcium current ( $>50 \mathrm{pA}$ peak; Fig. $6 \mathrm{~A}$ ) is measurable within $1 \mathrm{~min}$ of myotube uncoupling, indicating that $I_{\mathrm{Ca}}$ is probably present prior to uncoupling. Since we have been unable to voltage clamp the coupled fibers, it is unclear exactly when $I_{\mathrm{Ca}}$ first appears. $I_{\mathrm{Ca}}$ magnitude develops continuously for the remainder of embryogenesis (Figs. $6 A, 7)$, approximately doubling in size between myotube uncoupling (13.25 hr AEL) and hatching (21 hr AEL). $I_{\mathrm{Ca}}$ has the most graded maturation of all the muscle currents (Fig. 7).

For completeness, we consider the glutamate-gated current at the developing neuromuscular synapse, which has been the subject of a considerably more detailed analysis (preceding companion article, Broadie and Bate, 1992). The glutamate-gated current was assayed by iontophoresis of L-glutamate at the de- 


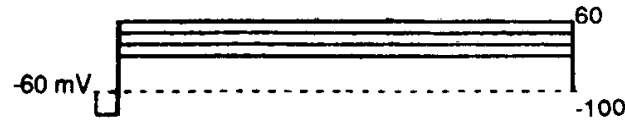

A

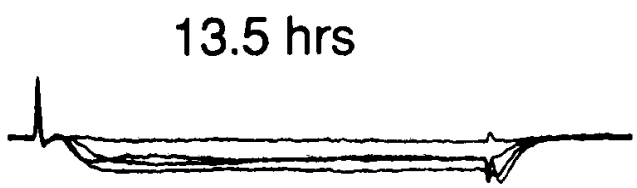

\section{$21 \mathrm{hrs}$}

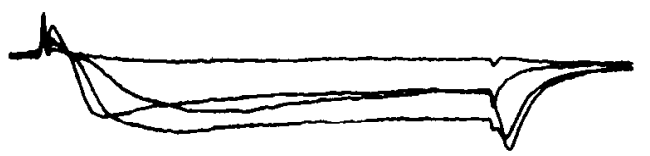

100 DA
3 ms

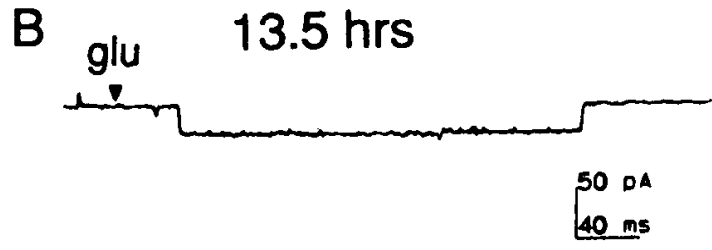

21 hrs

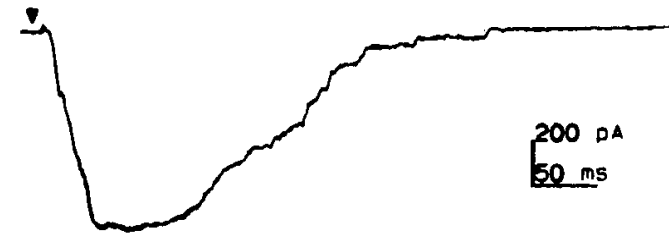

Figure 6. Development of the inward currents: the voltage-gated calcium current $\left(I_{C a}\right)$ and the L-glutamate-gated synaptic current at the developing NMJ. $A$, The calcium current was examined in the absence of the outward potassium currents by replacing intracellular $\mathrm{K}^{+}$with $\mathrm{Cs}^{+}$in whole-cell configuration (see Materials and Methods). High external calcium $(20 \mathrm{~mm})$ was used to emphasize the inward $I_{\mathrm{Ca}}$ in these traces. $I_{c \mathrm{a}}$ is the earliest detectable current in the embryonic myotubes, shown here at $13.5 \mathrm{hr}$ AEL, soon after myotube uncoupling. $I_{\mathrm{Ca}}$ increased only gradually through the later stages of embryogenesis $(21 \mathrm{hr}$ AEL, hatching). The myotubes are voltage clamped at $-60 \mathrm{mV} ;$ a $2 \mathrm{sec},-100$ $\mathrm{mV}$ prepulse precedes the voltage step to eliminate inactivation. Superimposed traces show voltage steps to $0,20,40$, and $60 \mathrm{mV}$. Each trace is the average of five trials. $B$, The glutamate-gated current was assayed by the iontophoresis of L-glutamate at the developing $\mathrm{NMJ}$ (Broadie and Bate, 1992). A small glutamate current was first observed at 13.25-13.5 hr AEL, soon after myotube uncoupling. The amplitude of this current increases rapidly throughout the later stages of embryogencsis and, at hatching ( $21 \mathrm{hr}$ AEL), is the largest conductance in the mature muscle. Myotube is voltage clamped at $-80 \mathrm{mV}$. Each trace is a single representative trial; at least 10 embryos were examined at each time point.

veloping synaptic zone. In common with $I_{\mathrm{\Lambda}}$ and $I_{\mathrm{K}}$, glutamategated current first develops within several minutes following myotube uncoupling at $13-13.25 \mathrm{hr}$ AEL. The initial current is small $(<20 \mathrm{pA}$ at $-80 \mathrm{mV}$; Fig. $6 B)$ and appears to represent the opening of a single, large-conductance, glutamate-gated channel (Broadie and Bate, 1992). However, the current rapidly increases in amplitude and has reached an amplitude of $>250$ pA (at $-80 \mathrm{mV}$ ) within $2 \mathrm{hr}$ (by $15.5 \mathrm{hr}$ AEL), and so parallels the rapid maturation of the $I_{\mathrm{A}}$ current (data not shown, but see Broadie and Bate, 1992). A more gradual but still rapid increase continues through to the end of embryogenesis, and at hatching (21 hr AEL; Fig. 6B) the synaptic glutamate-gated current is the largest conductance in the mature embryonic muscle.

\section{Development of myotube voltage responses}

In parallel with the maturation of the whole-cell currents, the voltage response of the embryonic myotube varies dramatically with developmental stage (Fig. 8). During the initial stages of myogenesis, while the myotubes are still coupled, they have a completely passive response to current injection (Fig. 8); most of the current flows through the nonrectifying gap junctions, and very little voltage change is elicited in the injected myotube. Immediately after uncoupling (13-13.25 hr AEL), current injection elicits a much greater change in myotube voltage, but the response remains largely passive. In the early myotube (13.5$14 \mathrm{hr} \mathrm{AEL}$ ), the first voltage response to depolarizing current is observed, with a small inward rectification with a threshold of -10 to $-20 \mathrm{mV}$ (Fig. 8). With increased current injection, the delay initially observed in this response is removed and the myotube is rapidly depolarized for the length of the stimulus.

Surprisingly, given the current development, no evidence for a hyperpolarizing response is observed at any time during these early stages (Fig. 8). Although $I_{\mathrm{A}}$ is prominent in voltage-clamp recordings, it is almost completely inactivated at the physiological resting potential ( $-46 \mathrm{mV}$; see below) and so does not contribute significantly to the response shown (see below). The influence of $I_{\mathrm{A}}$ can only be seen if the myotube is hyperpolarized to below $-80 \mathrm{mV}$ by injection of constant current. At this artificial potential, the myotube displays a large, though transient, rapid outward rectification (data not shown). At early stages, the inward $I_{\mathrm{Ca}}$ is dominant to the outward $I_{\mathrm{K}}$, and this, presumably, explains why a small inward rectification is the observed voltage response in these early stages.

A second development in voltage response commences by 15 hr AEL and reaches maximal effect by $18 \mathrm{hr}$ AEL (Fig. 8); that is, there is an increasing restriction of voltage depolarization to below $0 \mathrm{mV}$. During earlier periods ( $<15 \mathrm{hr} \mathrm{AEL}$ ), increasing injection of positive current depolarizes the myotube to increasingly positive values. After this period (starting $15 \mathrm{hr} A E L$ ), increasing injection of positive current will initially depolarize the myotube, but depolarization is restricted to $0 \mathrm{mV}$. By $18 \mathrm{hr}$ AEL, even the injection of relatively large currents $(>200 \mathrm{pA})$ will not depolarize the myotube above $0 \mathrm{mV}$ (Fig. 8).

During late embryogenesis ( $>18 \mathrm{hr}$ AEL), a third stage of voltage responsiveness develops (Fig. 8). During this period (18$21 \mathrm{hr} \mathrm{AEL}$ ), the myotube gradually develops an active, regenerating voltage response to depolarizing current injection. Initially (18.5-19.5 $\mathrm{hr} \mathrm{AEL),} \mathrm{this} \mathrm{development} \mathrm{is} \mathrm{signaled} \mathrm{by} \mathrm{spo-}$ radic, overshooting potentials with a threshold of approximately $-10 /-20 \mathrm{mV}$ and peak of +10 to $+15 \mathrm{mV}$; however, in general, voltage responses are still restricted to below $0 \mathrm{mV}$ as with earlier stages. Slightly later (20-21 hr AEL; Fig. 8), this restriction has been completely eliminated; the myotube shows a regenerative, active potential with a threshold of $-10 /-20 \mathrm{mV}$, peak of +20 to $+30 \mathrm{mV}$, and duration of $50-60 \mathrm{msec}$. In the hatching embryo $(21 \mathrm{hr} \mathrm{AEL})$, the membrane voltage response to injected depolarizing current consists of rapid, action potential-like spikes 


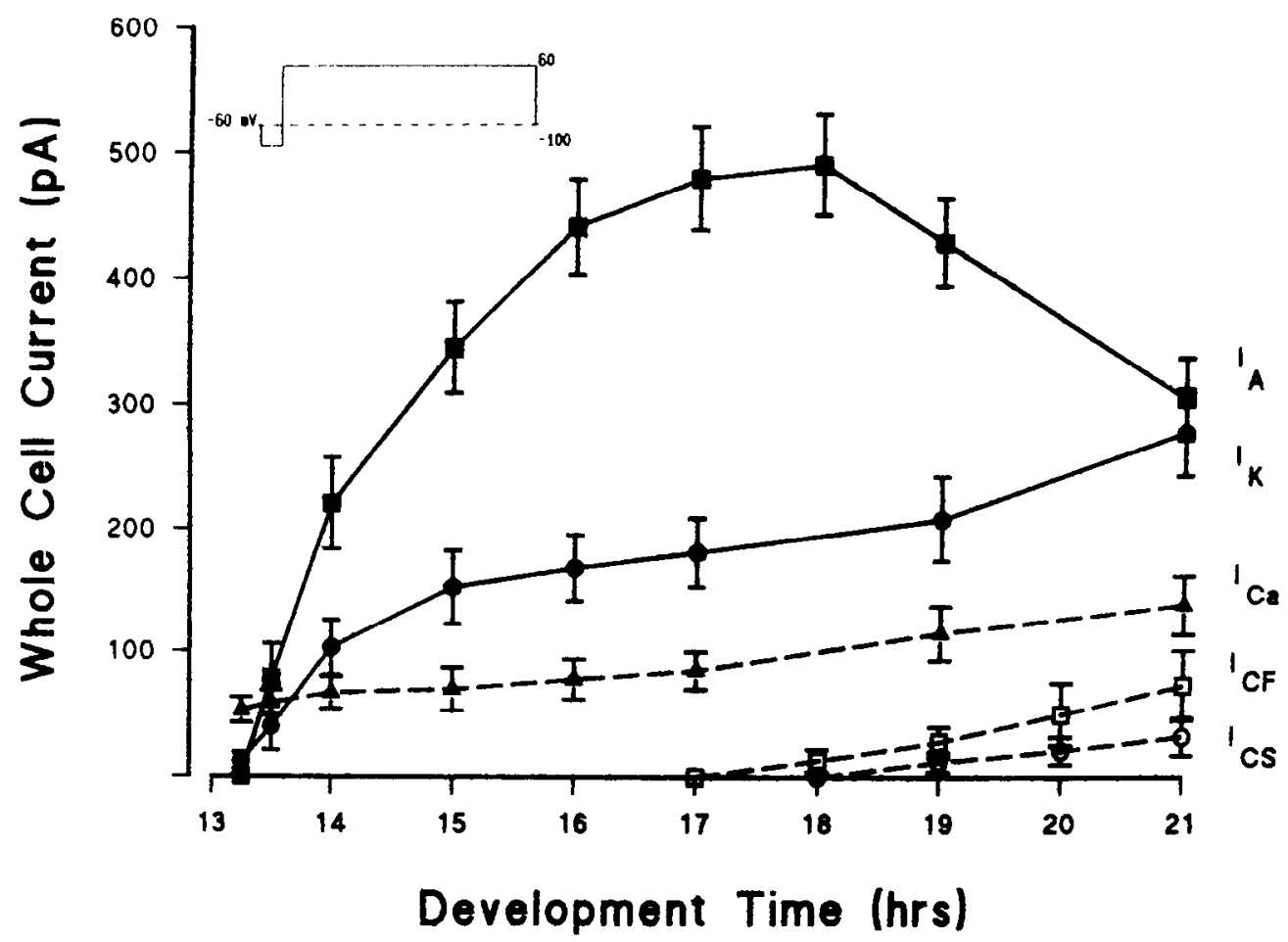

Figure 7. Development of the five components of the whole-cell voltagegated current: $I_{C_{\mathfrak{C}}}, I_{\mathrm{A}}, I_{\mathrm{CT}}, I_{\mathrm{K}}$, and $I_{\mathrm{CS}}$. The calcium current is the first to appear in the embryonic myotubes. The voltage-gated currents, $I_{\mathrm{A}}$ and $I_{\mathrm{K}}$, both appear early in development; $I_{\mathrm{K}}$ increases steadily through development, but $I_{A}$ increases rapidly, peaks, and declines sharply prior to hatching. The calcium-dependent currents, $I_{C r}$ and $I_{(}$, are the last to appear, arising late in embryogenesis and achieving only a relatively small amplitude by hatching (21 hr AEL). The peak current is measured in response to a voltage step from $\mathrm{a}-100 \mathrm{mV}$ prepulse $(2 \mathrm{sec})$ to $+60 \mathrm{mV}$. Each point shows the mean \pm SD for at least 10 embryos $(N=10)$. Current separation techniques are detailed in the Materials and Methods. that overshoot $0 \mathrm{mV}$ and continue without adaptation for the length of the current injection.

\section{An embryonic $\mathrm{I}_{A}$ current encoded by Shaker with a negatively shifted inactivation range}

Four of the five embryonic myotube currents $\left(I_{\mathrm{Ca}^{\mathrm{a}}}, I_{\mathrm{K}}, I_{\mathrm{CF}}\right.$, and $\left.I_{(\mathrm{S}}\right)$ have characteristics similar to the mature currents described in the third instar larva (Singh and Wu, 1990); that is, they have grossly similar activation/inactivation ranges assayed at the whole-cell level. In contrast, the $I_{\mathrm{A}}$ current in the early embryonic myotube has a midpoint of inactivation $40 \mathrm{mV}$ more negative than the mature $I_{\mathrm{A}}$ current, though the activation curve remains similar (Figs. 9, 10). Nevertheless, $I_{\mathrm{A}}$ current at all stages of development can be completely eliminated by a mutation at the Shaker locus ( $S h^{\mathrm{k} \$ 133}$; Fig. 4), indicating that the channels undcrlying the $I_{\mathrm{A}}$ current throughout myogenesis are encoded, at least in part, by the Shaker gene. We conclude that an embryonic and mature form of the Shaker channel exist in the developing Drosophila muscles.

During the initial stages of $I_{\mathrm{A}}$ electrogenesis (13.5-14 hr AEL), the $I_{\mathrm{A}}$ current has a very negative inactivation curve (Figs. 9, 10); the first significant removal of inactivation occurs at -50 to $-60 \mathrm{mV}$, and complete removal of inactivation is not achieved even after a $2 \mathrm{sec}$ prepulse at $-80 \mathrm{mV}$. During the mid-stages of $I_{\mathrm{A}}$ development (16-18 hr AEL; Figs. 9, 10), the inactivation curve develops a biphasic character. The initial stage $(0$ to -60 $\mathrm{mV}$ ) is similar to the mature relationship, with significant removal of inactivation by $-20 \mathrm{mV}$. The second stage ( -60 to $-100 \mathrm{mV}$ ) is similar to earlier development, in that a substantial removal of inactivation commences at $-60 \mathrm{mV}$ and continues through $-100 \mathrm{mV}$ (Figs. 9, 10). Even by $18 \mathrm{hr}$ AEL, significant $I_{\mathrm{A}}$ current remains inactive after a $2 \mathrm{sec}$ prepulse at $80 \mathrm{mV}$. Thus, it appears that at least two populations of channels are present that differ in their inactivation range. By hatching (21 hr AEL), an inactivation curve similar to that in the larva is observed (Figs. 9, 10), with a midpoint of inactivation at -35
$\mathrm{mV}$ and complete removal of inactivation by $-60 \mathrm{mV}$. It appears that two forms of the $I_{\mathrm{A}}$ current are expressed progressively: an early form with a very negative inactivation curve is progressively replaced with the mature form of the current as embryogenesis proceeds. The mechanism and significance of this developmental shift remain to be investigated.

The earliest $I_{\mathrm{A}}$ current $(13.5-15 \mathrm{hr}$ AEL), is strongly inactivated at the physiological resting potential $(-46 \pm 6 \mathrm{mV})$. This suggests that the early rapid maturation of the $I_{\mathrm{A}}$ current may be misleading in that most or all of this current may be functionally inactive. Therefore, the myotube may experience a much later and more gradual onset of the $I_{\mathrm{A}}$ current as the mature $I_{\mathrm{A}}$ current, with a much more positive inactivation curve, develops (Fig. 10). The physiological role of the abundant, early $I_{\mathrm{A}}$ current remains obscure.

\section{Discussion}

\section{Development of muscle currents}

The development of the voltage-gated muscle currents in the Drosophila embryo follows a clear progression: first the inward $\mathrm{Ca}^{2+}$ current $\left(I_{\mathrm{Ca}}\right)$ appears, then the voltage-gated outward $\mathrm{K}+$ currents $\left(I_{\mathrm{A}}, I_{\mathrm{K}}\right)$, and finally the calcium-dependent $\mathrm{K}$ currents $\left(I_{\mathrm{CF}}, I_{\mathrm{CS}}\right)$. Before the myotubes uncouple (13-13.25 hr AEL), $I_{\mathrm{Ca}}$ appears to be the only macroscopic current present in the myotubes, though we were unable to perform voltage-clamp experiments on the early, coupled muscles. Uncoupling correlates with the rapid onset of electrogenesis, with $I_{\mathrm{A}}, I_{\mathrm{K}}$, and the synaptic L-glutamate-gated currents all appearing within several minutes. The calcium-dependent $\mathrm{K}^{+}$currents do not appear until much later, near the end of embryogenesis.

Each current matures with a characteristic time course. For most of these currents, this maturation is unremarkable, involving a gradual increase in current amplitude from first appearance through to the end of embryogenesis. A striking exception is the $I_{\mathrm{A}}$ current encoded by the Shaker locus, which matures rapidly upon appearance, peaks in the late embryo, and 


\section{$13 \mathrm{hrs}$}

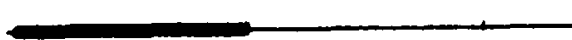

\section{$14 \mathrm{hrs}$}

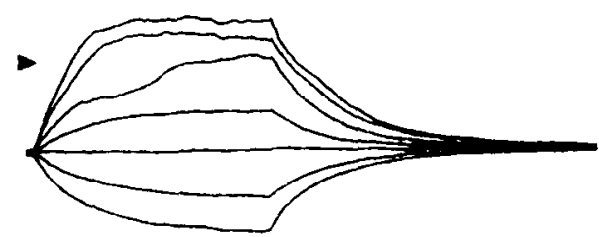

\section{$18 \mathrm{hrs}$}

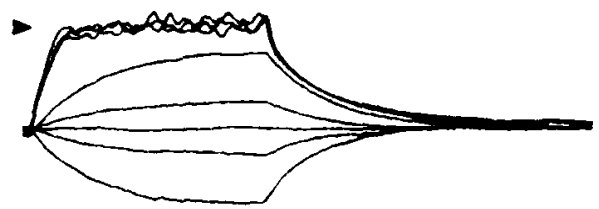

\section{1 hrs}

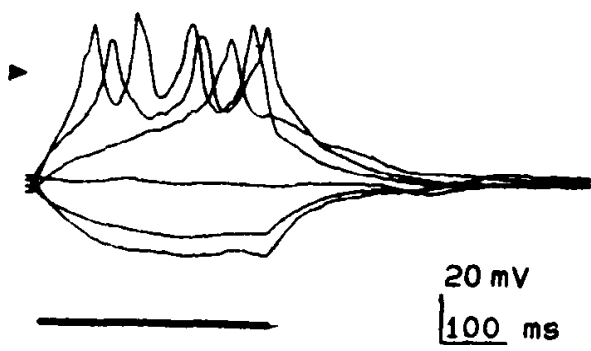

Figure 8. Development of the whole-cell voltage response in currentclamped embryonic myotubes. Constant current was injected from -50 $\mathrm{pA}$ in $25 \mathrm{pA}$ increments; bar length indicates injection duration; resting potential, $-46 \pm 6 \mathrm{mV}$; arrowheads indicate $0 \mathrm{mV}$. During early myogenesis (13 hr AEL), the myotubes are electrically coupled and show a completely passive response to current injection. By $14 \mathrm{hr} \mathrm{AEL}$, the myotubes are uncoupled but show only a small positive rectification in response to depolarizing current. By 18 hr AEL, a larger outward rectification is apparent, but voltage responses are restricted to $0 \mathrm{mV}$, even in response to large depolarizing currents $(+150 \mathrm{pA})$. At hatching (21 hr AEL), the myotube has developed a dynamic, regenerating potential response to depolarizing current injection. The threshold of this potential response is -10 to $-20 \mathrm{mV}$; the peak, +20 to $+30 \mathrm{mV}$; and the regenerating potential continues for the duration of current injection. Each trace is a single representative trial; at least 10 embryos were tested at every time point.

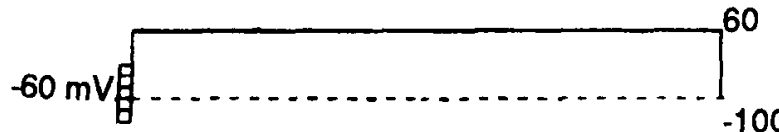

\section{$14 \mathrm{hrs}$}

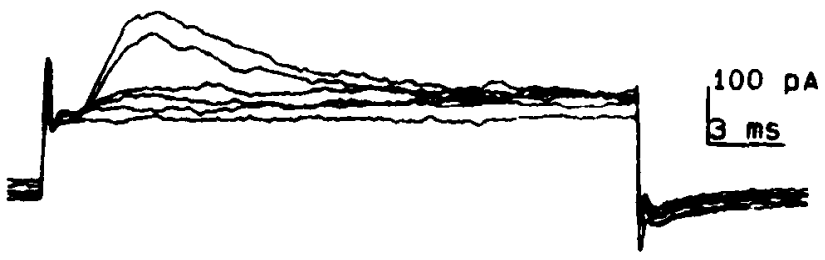

$18 \mathrm{hrs}$

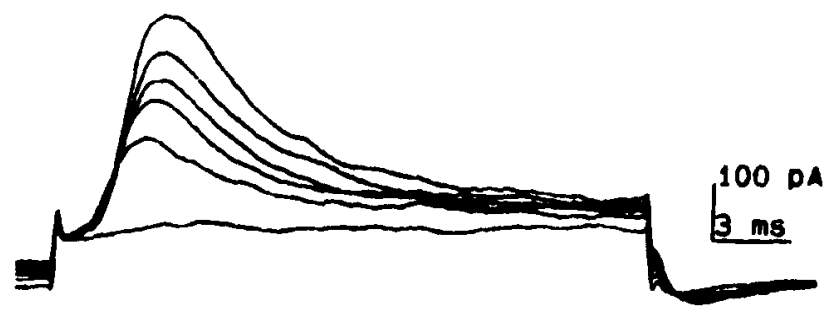

\section{$21 \mathrm{hrs}$}

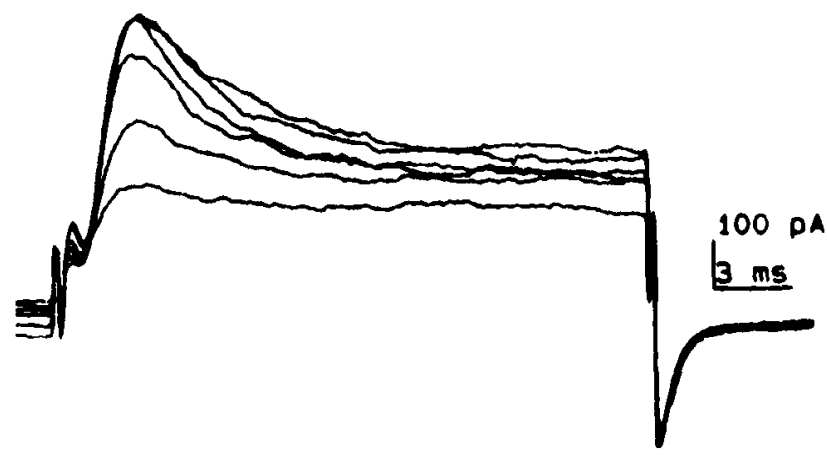

Figure 9. Development of the steady-state inactivation profile of wholecell currents in the embryonic myotubes (myotube 6 ). A prepulse $(2$ sec), starting from $0 \mathrm{mV}$ and decreasing in $-20 \mathrm{mV}$ increments $(0,-20$, $-40,-60,-80$, and $-100 \mathrm{mV}$ ), was followed by a voltage step to +60 $\mathrm{mV}$. In young myotubes ( $14 \mathrm{hr}$ AEL), the whole-cell current was strongly inactivated even at $-60 \mathrm{mV}$. By $18 \mathrm{hr}$ AEL, the midpoint of inactivation has shifted more positive and a prepulse of $-20 \mathrm{mV}$ is sufficient to activate significant current. However, complete removal of inactivation is not achieved even with a $-80 \mathrm{mV}$ prepulse. At hatching ( $21 \mathrm{hr} \mathrm{AEL}$ ), the midpoint of inactivation has become much more positive; complete removal of inactivation is achieved by $-60 \mathrm{mV}$. Notice the difference in time-to-peak between early $(14 \mathrm{hr})$ and late $(21 \mathrm{hr})$ stages; the intermediate stage ( $18 \mathrm{hr} \mathrm{AEL}$ ) appears to be composed of two populations, with high inactivation ( -60 to $-100 \mathrm{mV}$ ) showing a time-to-peak similar to early stages and low inactivation $(-20,-40 \mathrm{mV})$ showing a timeto-peak similar to mature stages. Superimposed traces are the average of five trials each. 


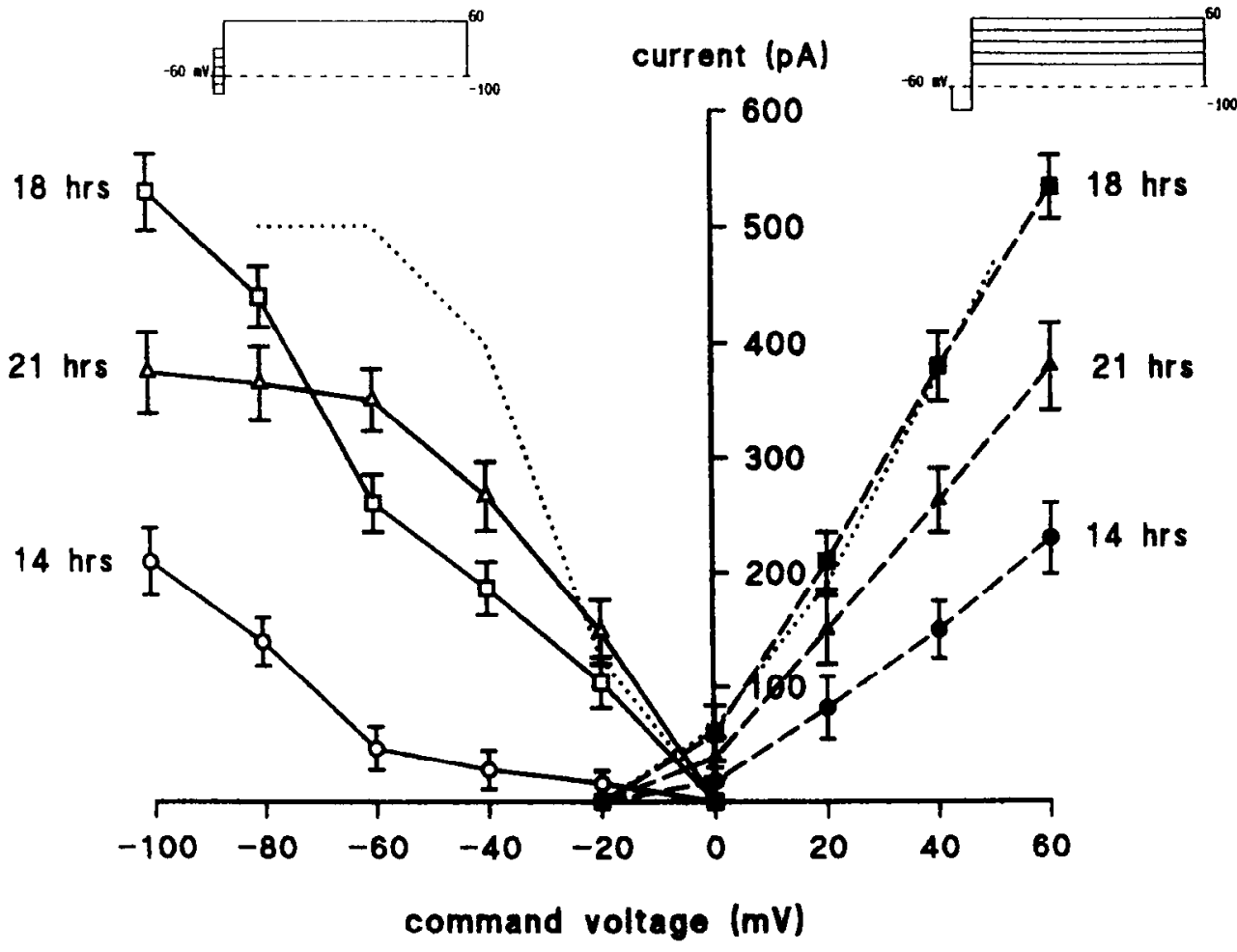

Figure 10. A comparison of the development of the activation and inactivation curves of the embryonic myotubes. The activation range (solid symbols) is on the right; the inactivation rangc (open symbols) is on the left. The protocols are presented as displayed earlier (see Figs. 2, 9). The midpoint of the inactivation curve changes dramatically with development: in early development (14 $\mathrm{hr} \mathrm{AEL}), I_{\mathrm{A}}$ is strongly inactivated even at $-60 \mathrm{mV}$; at $18 \mathrm{hr}$ AEL, the inactivation curve is biphasic with an initial inactivation curve $(0$ to $-60 \mathrm{mV}$ ) similar to the mature form, but with a late inactivation component $(-60$ to $-100 \mathrm{mV})$ similar to earlier development; by hatching ( $21 \mathrm{hr}$ AEL), the inactivation curve is monophasic with a midpoint of $-35 \mathrm{mV}$ and saturation reached by $-60 \mathrm{mV}$. Hence, a low-inactivation $I_{\mathrm{A}}$ current is present during earlier myogenesis and progressively replaced by the mature form as development proceeds. The dotted relationships reflect the activation and inactivation curves from mature cultured embryonic myotubes (Solc et al., 1987) and are included for comparison. Each point is the mean \pm SD of at least 10 embryos $(N=10)$ declines markedly prior to hatching. This late decline in $I_{\mathrm{A}}$ amplitude may be attributed to removal of an "embryonic" $I_{\mathrm{A}}$ channel (see below). The function of this unusual developmental time course remains unclear.

In the present study, we have limited our developmental analysis to well-characterized currents present in the mature Drosophila larval muscles (Singh and Wu, 1990). However, previous studies on cultured embryonic myotubes (Aldrich et al., 1989) have identified as many as six distinct classes of potassium channels, including two A-type channels, one delayed rectifier, two nonactivating channels, and a stretch-activated channel, none of which are calcium dependent. It is possible that the two A-type channels represent the early and late $I_{\mathrm{A}}$ types we have described in whole-cell recordings. Likewise, it is possible that the whole-cell $I_{\mathrm{K}}$ described here is composed of subpopulations of different $I_{\mathrm{K}}$ channel types. Indeed, our inability to eliminate $I_{\mathrm{K}}$ completely with quinidine suggests populations of $I_{\mathrm{K}}$ channels with different quinidine sensitivities. On the other hand, previous studies on cultured embryonic myotubes (Leung and Byerly, 1991) have identified only a single type of $\mathrm{Ca}^{2+}$ channel, whose properties suggest that it is the same as that shown in whole-cell recordings in the present study. A similar study has not been conducted on the $\mathrm{Ca}^{2+}$-gated $\mathrm{K}^{+}$channels in the embryo, so it remains to be demonstrated whether the whole-cell currents described here are composed of single- or multiplechannel populations.

The development of muscle currents in the pupa [flight muscles (DLMs)] and the embryo (abdominal muscle 6) of Drosophila is remarkably similar. In both cases, the voltage-gated $\mathrm{K}^{+}$currents $\left(I_{\mathrm{A}}, I_{\mathrm{K}}\right)$ arise very early in development and the calcium-dependent $\mathrm{K}^{+}$currents $\left(I_{\mathrm{CF}}, I_{\mathrm{CS}}\right)$ arise only very late, immediately prior to hatching (embryo) or following eclosion (pupa) (Salkoff, 1985; Elkins and Ganetzky, 1988). Hence, the voltage-gated $\mathrm{K}^{+}$currents are the only repolarizing currents present during development. The primary difference between the DLMs and the embryonic muscles is in the development of the inward calcium current $\left(I_{\mathrm{Ca}}\right)$. In the embryo, this is the first macroscopic current to appear; in the pupa, $I_{\mathrm{Ca}}$ appears only very late in development, immediately prior to eclosion (Salkoff, 1985). Presumably, therefore, the DLMs are noncontractile during development whereas the embryonic muscles not only are contractile, but are vigorously active throughout late development. This vigorous movement is a characteristic of embryonic development in all characterized species, vertebrate (Blackshaw and Warner, 1976; Dennis et al., 1981) and invertebrate (Bentley et al., 1979; Broadie et al., 1991), and has been suggested to play a role in muscle development, NMJ development, or both. Hence, it is likely that the late maturation of $I_{\mathrm{Ca}}$ is a specialization in the adult flight muscles and that the early maturation of $I_{C a}$ in the embryo represents the more general case.

There has been considerable speculation about the apparent functional redundancy of the voltage-gated $\left(I_{\mathrm{A}}, I_{\mathrm{K}}\right)$ and calciumdependent $\left(I_{\mathrm{CF}}, I_{\mathrm{CS}}\right) \mathrm{K}^{+}$currents. Both appear to function to repolarize the muscle to a resting state after excitation, and both have similar physiological propertics (Elkins and Ganctzky, 1988; Singh and $\mathrm{Wu}, 1990)$. It is interesting in this light to note that the calcium-dependent $\mathrm{K}^{+}$currents are absent for most of embryogenesis, appear only soon before hatching, and even in the hatchling embryo contribute negligibly to the repolarizing $\mathrm{K}^{+}$ current. It appears, therefore, that the voltage- and calciumdependent $\mathrm{K}^{+}$currents play developmentally distinct roles in the muscles, with the voltage-gated $I_{\mathrm{A}} / I_{\mathrm{K}}$ acting in isolation in the developing embryo and $I_{\mathrm{CF}} / I_{\mathrm{CS}}$ contributing significantly only to the mature state. In mature muscles, $I_{\mathrm{CF}}$ appears to play a dominant role in repolarization while $I_{\mathrm{A}}$ is secondary (Elkins and Ganetzky, 1988; Singh and Wu, 1990). Indeed, the complete elimination of $I_{\mathrm{A}}$ has only a small effect on the time course of repolarization (Elkins and Ganetzky, 1988), though $I_{\mathrm{A}}$ plays an 
important role in the delay of action potential initiation. Therefore, the early developmental role of $I_{\mathrm{A}}$ appears to be replaced, at least in part, by $I_{\mathrm{CF}}$ in the mature muscle. The reason for this developmental progression is unclear.

It has been speculated that there may be an evolutionary relationship between the voltage- and calcium-gated $\mathrm{K}^{+}$channels. Specifically, it has been suggested that $I_{\mathrm{CF}}$ may have evolved as a more precise form of repolarizing control in muscle, as it is directly regulated by calcium entry, sharing a common signal with muscle contraction (Salkoff, 1985). Control of intracellular calcium may be regarded as the crucial link between electrical signals and cellular activity. In development, the feedback mechanism in this circuit is indirect, proceeding through $I_{\mathrm{A}} / I_{\mathrm{K}}$ activated solely by membrane depolarization. In the mature muscles, a direct link exists between cytoplasmic calcium levels and muscle repolarization/relaxation via the calcium-dependent $\mathrm{K}^{+}$currents. In principle, this direct link forms a more precise and efficient feedback system for controlling $\mathrm{Ca}^{2+}$ entry and thus muscular activity.

\section{Development of the muscle voltage response}

The developmental progression of voltage responsiveness in the embryonic myotubes is similar to that observed during the pupal development of the adult DLMs (Salkoff, 1985). An early passive voltage response is replaced by a small rectifying response in mid-stages, and is followed by the development of an active, regenerating response very late in development, just prior to hatching (embryo) or following eclosion (pupa). The primary differences are as follows: (1) The early rectifying responses have opposite polarities, outward in pupal muscles and inward in embryonic muscles. Presumably, this reflects the very late development of $I_{\mathrm{Ca}}$ in the pupa relative to the embryo. It is noteworthy that in both cases a contribution of $I_{\mathrm{A}}$ is not observed, as it is wholly inactivated in early muscle development (Salkoff, 1985), though the mechanisms may differ (see below). (2) The "depolarization restriction" transiently observed in mid-stages (16-18 hr AEL) of the embryo is not reported in the pupal muscles. This possibly reflects the rather later development of $I_{\mathrm{K}}$ in the pupa relative to the embryo (Salkoff, 1985), though it is unclear how the "depolarization restriction" at $0 \mathrm{mV}$ is produced.

In newly eclosed adult flies, $I_{\mathrm{A}}$ plays the primary role in muscle (DLM) repolarization during action potential generation, but this role is quickly taken by the developing $I_{\mathrm{CF}}$ (Elkins and Ganetzky, 1988). Thus, elimination of $I_{\mathrm{A}}$ in early development affects action potential duration and frequency, as $I_{C F}$ elimination does in the mature fly, but elimination of $I_{\mathrm{CF}}$ in the immature fly has only very slight effects (Elkins and Ganetzky, 1988). These results suggest a developmental change in the relative amplitudes of $I_{\mathrm{A}}$ and $I_{\mathrm{Ca}}$ currents controls early action potential generation in the DLMs. A wholly analogous case is observed in the late embryo, where an apparent decline in $I_{\mathrm{A}}$ amplitude and increase in $I_{\mathrm{Ca}}$ amplitude precede the ability to generate action potentials. It seems, therefore, that the generation and regulation of muscle action potentials are very similar in embryonic and pupal development. We notc, however, that at the physiological resting potential $(-46 \mathrm{mV}), I_{\mathrm{A}}$ amplitude actually increases continuously throughout embryogenesis (Fig. 10 ), so the apparent decline in $I_{\mathrm{A}}$ amplitude observed in our voltage-clamp protocol does not appear to be involved in this process. Therefore, it is more probable that $I_{\mathrm{Ca}}$ attains some necessary threshold amplitude for the generation of action po- tentials only toward the end of embryogenesis. Though $I_{\mathrm{CF}}$ and $I_{\mathrm{CS}}$ appear soon before action potential generation in the embryonic muscles, they are unlikely to be involved in the generation of this response, as they are of small amplitude and, in the larva at least (Singh and Wu, 1990), appear antagonistic to action potential generation.

Most reports suggest that the mature larval muscles are incapable of generating action potentials, responding to depolarizing current passively (Jan et al., 1977; Wu and Ganetzky, 1988). However, we report that mature embryonic muscles respond to constant depolarizing current with a train of regenerating action potentials. There are two possible explanations for this apparent discrepancy. First, it is possible that larval muscles do generate action potentials; experiments with aerated larval preparations (Yamaoka and Ikeda, 1988), or with artificially hyperpolarized muscle resting potentials (Singh and $\mathrm{Wu}$, 1990), have shown that larval muscles are capable of firing action potentials. However, we must stress that nonaerated embryo preparations at the physiological resting potential readily produce trains of action potentials whereas the larval preparations manifestly do not under similar conditions. Second, the difference may be explained by the influence of the calciumdependent $\mathrm{K}^{+}$currents $\left(I_{\mathrm{CF}}, I_{\mathrm{CS}}\right)$. Experiments in the mature larva have shown that $I_{\mathrm{CF}}$ is the major contributor to muscle repolarization and acts to suppress action potentials (Singh and $\mathrm{Wu}, 1990)$. In mutations eliminating $I_{\mathrm{CF}}(s l o)$, all-or-none action potentials are much more readily produced in the mature larval muscles (Singh and $\mathrm{Wu}, 1990$ ). Both $I_{\mathrm{CF}}$ and $I_{\mathrm{CS}}$ have a small amplitude in the hatchling embryo and contribute negligibly to the repolarizing $\mathrm{K}^{+}$current. Hence, the conditions are similar in the mature embryonic muscle to larval muscles with a null slo mutation, and the muscles respond similarly by generating action potentials. At present, we cannot distinguish the above two possibilities. It is of interest to establish whether the ability to generate action potentials is a transient stage of muscle development or is the mature state of the larval muscles.

Although we can, perhaps, explain the dynamic changes in muscle voltage response during embryogenesis, it is much more difficult to speculate on their functional significance. In early development, for example, it has been suggested that the lateral spread of depolarization between coupled myotubes plays a role in regulating or synchronizing the early stages of muscle development in vertebrate embryos (Dennis et al., 1981), and may be similarly important in Drosophila. Likewise, it is possible that later voltage response regulation may play a role in muscle development. For example, the depolarization restriction in midmyogenic stages (16-18 hr AEL) correlates with the onset of vigorous muscle activity and may play a role in moderating or regulating muscle activity during early, delicate stages. A similar argument might suggest that the development of action potentials in late embryogenesis may signal or regulate late-developing muscle characteristics. So far, there has been no experimental verification of these intriguing correlations.

\section{An embryonic form of Shaker?}

Variants of the $I_{\mathrm{A}}$ current are present in many different tissues of the fly in both larval (Aldrich et al., 1989; Schwarz et al., 1990) and adult stages (Elkins and Ganetzky, 1988; Hardie et al., 1991). Many of these variants show differences in their voltage operating range. This rich diversity of $I_{\mathrm{A}}$ currents raises the possibility that varying forms of $I_{\mathrm{A}}$ channels may be expressed, not only in different tissues, but in the same tissue at 
developmentally distinct periods and, perhaps, with distinct functional consequences. Some of these $I_{\mathrm{A}}$ channels may be encoded by different structural genes (Solc and Aldrich, 1988; Wei et al., 1990), but at least two, one in larval and pupal muscle (Salkoff, 1985; Zagotta et al., 1988; Singh and Wu, 1990) and one in pupal and adult photoreceptors (Hardie et al., 1991), are encoded by the Shaker locus and can be eliminated by a null mutation of the Shaker structural gene.

In the present study, we have revealed two variant forms of the $I_{\mathrm{A}}$ current that are expressed in a progressive fashion in the developing embryonic myotubes. The earlier, "embryonic" form has a midpoint of inactivation $40 \mathrm{mV}$ more negative than the mature form found in the hatchling embryo and larval muscles. Initially, only the "embryonic" $I_{A}$ current is present. During late embryogenesis, the inactivation curve is biphasic, indicating two populations of $I_{\mathrm{A}}$ channels, embryonic and larval, and in the hatchling embryo only a single $I_{\mathrm{A}}$ current remains, sharing similar inactivation characteristics with the mature larval $I_{\mathrm{A}}$ current. The $I_{\mathrm{A}}$ current at all stages can be eliminated by a mutation in the Shaker locus $\left(S h^{\mathrm{KS} 133}\right)$. We conclude that an embryonic form of the Shaker channel is present in the young embryonic myotubes and is progressively replaced by the mature form during late embryogenesis.

It has recently been demonstrated that the voltage dependence of different Shaker channels can vary dramatically. Shaker channels in both the adult Drosophila photoreceptors (Hardie et al., 1991) and pupal neurons (Baker and Salkoff, 1990) have a voltage operating range shifted $30-40 \mathrm{mV}$ more negative than that of Shaker channels in larval muscle. Likewise, we have seen a negative shift (of similar magnitude; $40 \mathrm{mV}$ ) in the inactivation range of a Shaker whole-cell current in the embryonic myotubes relative to the inactivation range in the larval muscles.

Previous work has shown that $I_{\mathrm{A}}$ diversity may arise through alternate mRNA splicing (Kamb et al., 1988; Schwarz et al., 1988), heteromultimeric $\mathrm{K}^{+}$channel structure (Haugland and Wu, 1990; Isacoff et al., 1990; Covarrubias et al., 1991), and multiple structural genes (Tempel et al., 1988; Covarrubias et al., 1991). At least 10 transcripts are encoded by alternative splicing of mRNA from the Shaker locus, at least in Xenopus oocytes (Kamb et al., 1988), but despite this potential diversity, only two kinetically distinct potassium channels have actually been shown to be encoded by Shaker in Drosophila (i.e., larval muscle and adult photoreceptors; Hardie et al., 1991). These different Shaker channels, as predicted, are encoded by different mRNA transcripts (Hardie et al., 1991). In the present study, we have the possibility of a third example: a distinct $I_{\mathrm{A}}$ current, encoded by the Shaker locus, that may arise though alternative splicing during early embryonic muscle development. This possibility has not yet been rigorously tested and requires further investigation.

The $I_{\mathrm{A}}$ current is one of the first voltage-gated currents to appear in the embryonic myotubes, matures much more rapidly than other currents, and so is the most prominent current in the voltage-clamped myotubes for most of embryogenesis. However, the inactivation characteristics of the early $I_{\mathrm{A}}$ current render it almost entirely inactive at the physiological resting potential. Moreover, during the early, dramatic increase in $I_{\mathrm{A}}$ amplitude, almost all of this current remains inactive under physiological conditions. It is only relatively late in development, with the emergence of the mature form of $I_{A}$, that the myotube experiences a substantial $I_{\mathrm{A}}$ current active under physiological conditions. These findings pose the interesting question of a function, if any, for this early, dramatic increase in $I_{\mathrm{A}}$ amplitude. It is possible that the $I_{\mathrm{A}}$ current is more active normally than under experimental conditions; perhaps it has a long time course of inactivation that can be removed by remaining at the resting potential for an extended period of time $(>5 \mathrm{sec}$ ). Alternatively, unknown mechanisms may hyperpolarize the myotube under normal conditions and so activate the abundant $I_{\mathrm{A}}$ current. For example, it has been reported that tracheal aeration of the mature larval muscles lowers the resting potential to $-80 \mathrm{mV}$, considerably lower than the -30 to $-60 \mathrm{mV}$ reported in unaerated preparations (Yamaoka and Ikeda, 1988). However, in vigorously aerated $\left(\mathrm{O}_{2}\right.$ supplied in bath), freshly dissected embryos ( $<3 \mathrm{~min}$ ), we never saw resting potentials more negative than $-60 \mathrm{mV}$, though tracheal aeration of the embryo was not attempted. Even if we accept a resting potential of $-60 \mathrm{mV}$, we find that most of the $I_{\mathrm{A}}$ current remains inactivated at this potential (Fig. 10). Thus, the question of the functional significance of the early embryonic $I_{\mathrm{A}}$ current, if any, remains unresolved and awaits further investigation.

\section{References}

Aldrich R, Solc C, Zagotta W, Brainard M (1989) Single potassium channcls in Drosophila nerve and muscle. In: Ion transport (ISBN), pp 73-85. New York: Academic.

Baker K, Salkoff L (1990) The Drosophila Shaker gene codes for a distinctive $\mathrm{K}^{+}$current in a subset of neurons. Neuron 4:129-140.

Bate M (1990) The embryonic development of larval muscles in Drosophila. Development 110:791-804.

Bentley D, Keshishian H, Shankland M, Toroian-Raymond A (1979) Quantitative staging of embryonic development of the grasshopper, Schistocerca nitens. J Embryol Exp Morphol 54:47-74.

Blackshaw S, Warner A (1976) Low resistance junctions between mesoderm cells during development of trunk muscles. J Physiol (Lond) 245:209-230.

Broadie K, Bate M, Tublitz N (1991) Quantitative staging of embryonic development of the tobacco hawkmoth, Manduca sexta. Rouxs Arch Dev Biol 199:327-334.

Broadie KS, Bate M (1993) Development of the embryonic neuromuscular synapse of Drosophila melanogaster. J Neurosci 13:144166.

Campos-Ortega J, Hartenstein V (1985) The embryonic development of Drosophila melanogaster. Berlin: Springer.

Covarrubias M, Wei A, Salkoff L (1991) Shaker, Shal, Shab, and Shaw express independent $\mathrm{K}^{+}$current systems. Neuron 7:763-773.

Crossley A (1978) The morphology and development of the Drosophila muscular system. In: The genetics and biology of Drosophila $2 \mathrm{~b}$ (Ashburner M, Wright T, eds), pp 499-560. London: Academic.

Currie D, Milner M, Fvans C (1988) The growth and differentiation in vitro of leg and wing imaginal disc cells from Drosophila melanogaster. Development 102:805-814.

Dennis M, Ziskind-Conhaim L, Harris A (1981) Development of neuromuscular junctions in rat embryos. Dev Biol 81:266-279.

Elkins T, Ganetzky B (1988) The roles of potassium currents in Drosophila flight muscles. J Neurusci 8:428-434.

Elkins T, Ganetzky B, Wu C-F (1986) A gene affecting a calciumdependent potassium current in Drosophila. Proc Natl Acad Sci USA 83:8415-8419.

Ganetzky B, Wu C-F (1986) Neurogenetics of membrane excitability in Drosophila. Annu Rev Genet 20:13-44.

Gho M, Mallart A (1986) Two distinct calcium-activated potassium currents in larval muscle fibers of Drosophila melanogaster. Pfluegers Arch 407:526-533

Hamill O, Marty A, Neher E, Sakmann B, Sigworth F (1981) Improved patch-clamp techniques for high-resolution current recording from cells and cell-free membrane patches. Pfluegers Arch 391:85-100.

Hardie R, Voss D, Pongs O, Laughlin S (1991) Novel potassium channels encoded by the Shaker locus in Drosophila photoreceptors. Neuron 6:477-486.

Jan L, Jan Y (1976a) Properties of the larval neuromuscular junction in Drosophila melanogaster. J Physiol (Lond) 262:189-214. 
Jan L, Jan Y (1976b) L-Glutamate as an excitatory transmitter at the Drosophila larval neuromuscular junction. J Physiol (Lond) 262:215236.

Jan Y, Jan L, Dennis M (1977) Two mutations of synaptic transmission in Drosophila. Proc R Soc Lond [Biol] 198:87-108.

Haugland F, Wu C-F (1990) A voltage-clamp analysis of gene-dosage effects of the Shaker locus on larval muscle potassium currents in Drosophila. J Neurosci 10:1357-1371.

Isacoff E, Jan Y, Jan L (1990) Evidence for the formation of heteromultimeric potassium channels in Xenopus-oocytes. Nature 345:530534.

Johansen J, I Ialpern M, Keshishian H (1989) Axonal guidance and development of muscle fiber-specific innervation in Drosophila embryos. J Neurosci 9:4318-4332.

Kamb A, Tseng-Crank J, Tanouye M (1988) Multiple products of the Drosophila Shaker gene may contribute to potassium channel diversity. Neuron 1:421-430.

Leung H-T, Byerly L (1991) Characterization of single calcium channels in Drosophila embryonic nerve and muscle. J Neurosci 11:30473059.

Marty A, Neher E (1983) Tight-seal whole-cell recording. In: Singlechannel recording (Sakmann B, Neher E, eds), pp 107-121. New York: Plenum.

Salkoff L (1983) Drosophila mutants reveal two components of fast outward current. Nature 302:249-251.

Salkoff L (1985) Development of ion channels in the flight muscles of Drosophila. J Physiol (Paris) 80:275-282.

Salkoff L, Wyman R (1981) Genetic modification of potassium channels in Drosophila Shaker mutants. Nature 293:228-230.

Schwarz T, Tempel B, Papazian D, Jan Y, Jan L (1988) Multiple potassium-channel components are produced by alternate splicing at the Shaker locus in Drosophila. Nature 331:137-142.

Schwarz T, Papazian D, Carretto R, Jan Y, Jan L (1990) Immunological characterization of $\mathrm{K}^{+}$channel components from the Shaker locus and differential distribution of splicing variants in Drosophila. Neuron 4:119-127.
Shields G, Sang J (1977) Improved medium for culture of Drosophila embryonic cells. Drosophila Inform Serv 52:161.

Singh S, Wu C-F (1990) Properties of potassium currents and their role in membrane excitability in Drosophila larval muscle fibers. J Exp Biol 152:59-76.

Solc C, Aldrich R (1988) Voltage-gated potassium channels in larval CNS neurons of Drosophila. J Neurosci 8:2256-2570.

Solc C, Zagotta W, Aldrich R (1987) Single-channel and genetic analyses reveal two distinct A-type potassium channels in Drosophila. Science 236:1094-1098.

Tempel B, Jan Y, Jan L (1988) Cloning of a probable potassium channel gene from the mouse brain. Nature 332:837-839.

Wei A, Salkoff L (1986) Occult Drosophila calcium channels and twinning of calcium and voltage-activated potassium channels. Science 233:780-782.

Wei A, Covarrubius M, Butler A, Pak K, Salkoff L (1990) K+ current diversity is produced by an extended gene family conserved in Drosophila and mouse. Science 248:599-603.

Wu C-F, Ganetzky B (1988) Genetic and pharmacological analyses of potassium channels in Drosophila. In: Neurotox '88: molecular basis of drug and pesticide action (Lunt G, ed), pp 311-323. Amsterdam: Elsevier.

Wu C-F, Haugland F (1985) Altered potassium conductances in larval muscle fibers of Shaker mutants of Drosophila. J Neurosci 5:26262640.

Yamaoka K, Ikeda K (1988) Electrogenic responses elicited by transmembrane depolarizing current in aerated body wall muscles of Drosophila melanogaster larvae. J Comp Physiol 163:705-714.

Zagotta W, Brainard M, Aldrich R (1988) Single-channel analysis of four distinct classes of potassium channels in Drosophila muscle. J Neurosci 8:4765-4779.

Zagotta W, Gereraad S, Garber S, Hoshi T, Aldrich R (1989) Properties of the ShB A-type potassium channels expressed in Shaker mutant Drosophila by germline transformation. Neuron 3:773-782. 